\title{
Laser Florence 2011
}

\section{......A Window on the Laser Medicine World}

For Researchers, Physicians, Surgeons, Biologists, Physical Therapists, Physics, Engineers

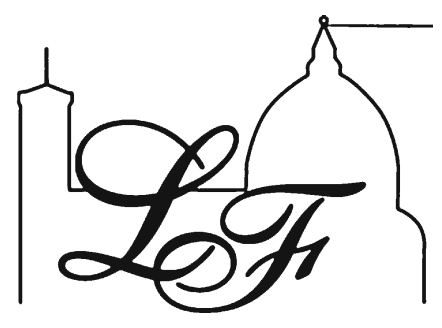

Florence, November $4^{\text {th }}-5^{\text {th }}, 2011$

Auditorium of Saint Apollonia, Via S. Gallo, 25 - Firenze

Lasers in Medical Science

Volume 26, Supplement 1, 2011

DOI 10.1007/s10103-011-0999-6

This supplement was not sponsored by outside commercial interests. It was funded entirely by the publisher.

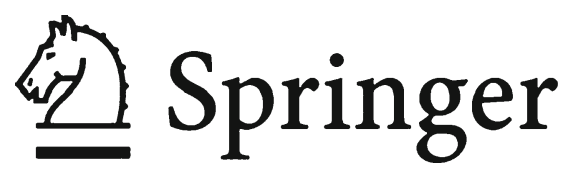


These abstracts are published exactly as received from the submitting authors. The opinions and views expressed are those of the authors and have not been verified by the Publishers or the editors, which accepts no scientific responsibility for the statements made or for the

accuracy of the data presented. Any typing or other errors are the authors' own. 


\section{I.A.L.M.S. — INTERNATIONAL ACADEMY LASER MEDICINE AND SURGERY}

$25^{\text {th }}$ International Congress Laser Medicine \& IALMS Courses

Jointly with the $4^{\text {th }}$ Biannual Congress of the International Phototherapy Association

\section{Laser Florence 2011}

Program Chairperson L. Longo, MD

\section{Organizing/Scientific Committee}

J. Anders, PhD; Y. Asagai, MD; K. Atsumi, MD; A. Baruchin, MD, PhD; G.D. Baxter, PhD; T. Dostalova, PhD;

C. Fornaini, DDS; S. Gonchukov, PhD; M. Herold, MD; H. Jelinkova, PhD; I. Kaplan, MD; K. Khatri, MD; R. Lubart, PhD;

G. Lynn-Powell, DDS; L. Navratil, PhD; T. Ohshiro, MD; V. Oswal, PhD; M.L. Pascu, PhD; A. Pinheiro, DDS;

M. Postiglione, MD; S. Rockhind, PhD; K. Russe, MD; J. Vaitkus, PhD; A. Vaitkuviene, PhD; W. Waidelich, PhD

Scientific (Organizing) Secretariat:

IALMS -

Borgo Pinti, 57 - 50121 Firenze

TEL \#39 0552342330

FAX \#39 05539069632

info@laserflorence.org

http://www.laserflorence.org

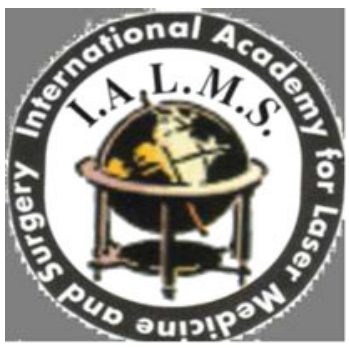




\section{PROGRAM AT-A-GLANCE}

November $4^{\text {th }}, 2011$

- PLENARY LECTURES Chairmen I. Kaplan, M. Pascu, J. Vaitkus

- LASER BIOMODULATION 1 - SCIENTIFIC RESEARCH AND CLINICAL PRACTICE Chairmen M. Herold, R. Lubart, N. Salanski

- LASER BIOMODULATION 2 - SCIENTIFIC RESEARCH AND CLINICAL PRACTICE Chairmen J. Anders, G.D. Baxter, L. Navratil

- TRENDS IN BASIC AND APPLIED RESEARCH IN LASER BIOMEDICINE Chairmen S. Gonchukov, H. Jelinkova, A. Vaitkuviene

17: 15 - Round Table with the Patients

19:15 - Open Ceremony with Welcome Cocktail and leading lecture

Provincia di Firenze, Palazzo Medici-Riccardi, Sala Luca Giordano
November $5^{\text {th }}, 2011$

- LASER DENTISTRY - Chairmen C. Fornaini, G. Lynn-Powell, A.L.B. Pinheiro

- LASER DENTISTRY and ENT - Chairmen A. Baruchin, T. Dostalova, B. Palmieri

- LASER NEUROSURGERY - Chairmen J. Chiu, A. Lauto, M. Stark

- LASER/LIGHT AND SKIN - Chairmen K. Khatri, T. Ohshiro, K Russe-Wilflingseder

- TALK POSTER SESSION - Chairmen M. Postiglione, P. Smalley

20:30 - Gala Dinner, Awards Assignation, Music show and Closure Ceremony 


\section{ORGANIZED BY}

I.A.L.M.S.

The International Academy for Laser Medicine and Surgery

\section{SPONSORED BY}

I.S.L.S.M.

The International Society of Laser Surgery and Medicine

W.F.L.S.M.S.

The World Federation of Laser Surgery and Medicine Societies

I. P.T.A.

The International Phototherapy Association

UNDER THE HIGH PATRONAGE OF

The President of Italian Republic

Italian Health Office

Provincia di Firenze

Florence Medical Association

Florence Convention Bureau

I.L.M.

Institute Laser Medicine Florence 


\section{CONFERENCE SCIENTIFIC BOARD}

○ J.J. Anders, BiD, PhD (USA) - Anatom/Cell Biol. Dept, Uniformed Serv. Univ., Bethesda

${ }^{\circ}$ Y. Asagai, MD (Japan) - Director, Shinano Handicapped Children Hospital, Suwa

${ }^{\circ}$ K. Atsumi, MD, PhD (Japan) - Professor Emeritus, Tokyo University

${ }^{\circ}$ A. Baruchin, MD, PhD (ISR) - Plastic Surgery Dept, Ben-Gurion Univ. Beer-Sheba, Askelon

${ }^{\circ}$ G.D. Baxter, TD, BSc, DPhil, MCSP (GB) - Dean, Otago Univ.(NZ), Sch.Health Sciences

- A. Bovero, PhD.(I) - President, CIDESCO Italy, Rome

$\circ$ J. Chiu, MD, PhD (USA) - California Spine Institute, Laser Neurospine Surgery Thousand Oaks

- T. Dostalova, MD (Czech Rep) - Charles Univ. 1st Medicine Faculty, Dept of Stomatology, Prague

${ }^{\circ}$ C. Fornaini, MD, DDS (I) - Odontostomatology Institute, Parma University

${ }^{\circ}$ S.A. Gonchukov, PhD (Russia) - Moscow State Engineering Physics Institute, Moscow, Russia

${ }^{\circ}$ M. Herold, MD, PhD (A) - Innsbruck Medical Univ., Dept of Internal Med, Innsbruck, Austria

${ }^{\circ}$ H. Jelinkova, MD, PhD(Czech Rep) - Czech Technical Univ. -Nuclear Sciences Phys.Eng, Prague

${ }^{\circ}$ I. Kaplan, MD, PhD (Israel) - Professor Emeritus, Tel Aviv University

${ }^{\circ} \mathrm{K}$. Khatri, MD, (USA) - Skin \& Laser Center, Boston

${ }^{\circ}$ A. Lauto, PhD (Australia) - University of Western Sydney

${ }^{\circ}$ G. Lynn-Powell, DDS, PhD (USA) - Ch., Dental Educ. Sch. Med. Utah Univ., Salt Lake City

${ }^{\circ}$ R. Lubart, BiD, PhD (ISR) - Biology Dept, Bar-Ilan University, Ramat-Gan

${ }^{\circ}$ L. Navratil, MD, PhD (Czech Rep) - Czech Technical University, Faculty of Biomedical Engineering, Kladno

${ }^{\circ}$ T. Ohshiro, MD, PhD (Japan) — Director, Japan Laboratory of Laser Medicine and Surgery, Tokyo

${ }^{\circ}$ B. Palmieri, MD (I) - Surgery Dept, Modena University

${ }^{\circ}$ A. Panti, MD (I) - President, Florence Medical Association

${ }^{\circ}$ A. Pinheiro, DDS, PhD (Brazil) - Dentistry Dept., Bahia University

${ }^{\circ}$ M.L. Pascu, PhSc, PhD (Rom) — Institute Atomic Physics; Physics Faculty, Bucharest University

${ }^{\circ}$ M. Postiglione, MD (I) - Former Director, W.H.O., Firenze

${ }^{\circ} \mathrm{K}$. Russe-Wilflingseder, MD (A) - Plastische Chirurgie und Laserzentrum, Innsbuck

${ }^{\circ}$ P. Smalley, TN (USA) - Tecnology Concepts International, Chicago

${ }^{\circ}$ M. Stark, MD, PhD (D) - NESA President, Berlin

${ }^{\circ}$ A. Vaitkuviene, MD, PhD (Lithuania) - Division of Biomedical Technology. Institute Applied Research.Vilnius University

$\circ$ J. Vaitkus, PhD (Lithuania) - President, Lithuanian Physical Society, Vilnius University 


\section{EUROPEAN NETWORKS GENERATED BY LASER FLORENCE CONFERENCES}

1997: Pulse light for vascular lesions, advantages and limits. Endovascular laser therapy for various veins. Indication and contraindications for Laser resurfacing procedures.

1998: mechanism of action, ant inflammatory and antiedema effects of Laser. Advantages and limits for laser in dentistry. Types of laser recommended for treatment of telangiectases and reticular veins.

1999: Prostatectomy laser. Non surgical endovenous laser modulating the immune system. Advantages and limits of Laser and IPL as hair removal techniques.

2000: PDD and PDT for the treatment of gastrointestinal and urological cancers. Laser therapy for wound healing and skin ulcers., stretch marks,scars, keloids. Laser and IPL in skin rejuvenation.

2001: Laser treatment for diabetes type 1 and 2 (live demonstration on patients during the congress, probably, for the first time in the world). Advantages and limits of pulsed light in aesthetic medicine and surgery. What kind of laser should be in rheumatology and sport traumas? Role of European Community and World Health Organization in these issues.

2002: Laser Treatment of disk Hernias. Laser and light treatment for Psoriasis and Vitiligo.

2003: Laser therapy for nervous cells regeneration, in vitro and experimental. Complications of laser and light therapy and their treatment. Selection of affordable instrumentation. Advantages and limits of laser in ophthalmology. Position of FDA and other International Institution on non surgical laser.

2004: laser therapy of spinal cord injuries in clinical practice; first diabetic patients treated with laser in Italy, following Helsinki declaration rules; news on mechanisms of ant inflammatory and regenerative effects of lasers on the human tissues; prostatectomy laser in day surgery; advantages and limits of endoluminal laser surgery of varicose veins; laser coupled with radio frequency scalpel for skin lesion treatment. Laser treatment of progenitor cells.

2005: Cesarean incision with laser. Photodyalisis laser for chronic degenerative conditions. Follow-up of laser therapy for diabetes. Laser therapy of traumatic spinal cord injuries. Action mechanism of laser beam on nervous tissue.
2006: Photopletismography multi laser in vascular diseases. News substances for PDT of lung cancer. Ant inflammatory and regenerative mechanisms of laser treatment of experimental myocardial infarct. News on Laser therapy in sport traumatology Radio protective effects of non surgical laser.

2007: Laser in stem cells therapy: preclinical phase. Laser therapy for traumatic and degenerative spinal cord injuries with live patients presentation. Follow-up of laser therapy in diabetes type 1 e 2. Laser therapy for female infertility. Laser vascular and aesthetic surgery. State-of-the art on laser dentistry and PDD/PDT.

2008: Laser in brain traumatic injuries; Laser therapy for male infertility. Laser and energetic medicine; laser and nervous progenitor cells.

2009: Guidelines for the use of non surgical lasers. Laser Diagnosis. Laser therapy for infertility. Laser and stem cells

2010: Follow up of positive results on central nervous system traumatic injuries. Laser therapy for peripheral nerve reconstruction. Laser therapy for prevention of central nervous system post-traumatic damages. Laser diagnosis of early cancer of lung, uterus, breast, urinary bladder, prosthate. Laser and photodynamic therapy of prosthate cancer and lung cancer. Laser therapy of the menopause. Light for improving the follow-up of laser therapy of diabetes. Laser and stem cells for treatment of myocardial lesions. 


\section{PLENARY LECTURES}

Room A - November $4^{\text {th }}, 2011$

Chairmen: I. Kaplan, M.Pascu, J. Vaitkus

09:00 LASER MEDICINE AND SURGERY TODAY Isaac Kaplan, MD

Professor Emeritus, Tel Aviv University

09:30 REGENERATIVE PHOTONIC THERAPY: REVIEW

Natasha Salansky and Norman Salansky

Millennium Health Institute, Ontario, Canada

10:00 WHICH LASER THERAPY COULD BE CALLED "QUANTUM MEDICINE"? A PHYSICIST'S VIEW

Hans A. Romberg, MD

Hans Romberg Medizintechnik, Heidelberg, Germany

10:30 LASER RADIATION INTERACTION WITH

FLUOROFORES IN MICRO-/NANO-DROPLETS

OF SOLUTIONS

M. L. Pascu, I. R. Andrei, V. Nastasa, M. Boni, G. V. Popescu

National Institute for Laser, Plasma and Radiation

Physics, Magurele, Romania

11:00 PHOTODIAGNOSIS IN PERSONALIZED MEDICINE

A. Vaitkuviene, MD, PhD, Juozas V. Vaitkus, Prof.Dr.Sc

Vilnius University, Lithuania

11:30 COFFEE-BREAK

\section{LASER BIOMODULATION - 1}

Room A - November $4^{\text {th }}, 2011$

Chairmen: M. Herold, R. Lubart, L. Navratil

11:45 THE USE OF VISIBLE LIGHT AND METAL OXIDES NANO PARTICLES FOR PATHOGENS INACTIVATION

R. Lubart, A. Gedanken and A. Lipovski

Departments of Chemistry and Physics, Bar-Ilan University

12:00 LASER PHOTOSTIMULATION OF WOUND HEALING IN DIABETIC MICE IS NOT CAUSED BY DIABETES-MODIFYING EFFECTS OF LASER LIGHT

Philip V. Peplow PhD ${ }^{\mathrm{a}}$, Tzu-Yun Chung a , G. David Baxter DPhil ${ }^{\mathbf{b}}$

${ }^{a}$ Department of Anatomy \& Structural Biology, and

${ }^{\mathrm{b}}$ Centre for Physiotherapy Research, School of Physiotherapy, Univ. of Otago, Dunedin, New Zealand
12:15 FIRST EXPERIENCE WITH COMBINED TREATMENT OF TEMPOROMANDIBULAR JOINT WITH USE OF LLLT.

L. Navratil, P. Hlinakova, T. Dostalova, V. Navratil, S. Hajkova

Czech Technical University in Prague, Faculty of Biomedical Engineering Biomedical and Clinical Technology, Kladno

12:30 EVALUATION OF LED PHOTOBIOMODULATION ON WOUND HEALING IN HYPOTHYROID AND EUTHYROID RATS

GM Paraguassúa ${ }^{a}$, FCA Xavier ${ }^{\mathrm{b}}$, TT Rodriguez ${ }^{\mathrm{c}}$, MJP Ramalho ${ }^{c}$, ALB Pinheiro ${ }^{a, d, e}$, LMP Ramalho $^{\mathbf{a}, \mathbf{b}}$

${ }^{\mathrm{a}}$ Center of Biophotonics, School of Dentistry, Federal University of Bahia, Salvador, Bahia, Brazil

${ }^{b}$ Laboratory of Surgical Pathology, School of Dentistry, Federal University of Bahia, Salvador, Bahia, Brazil

${ }^{\mathrm{c}}$ Department of Physiology, Instituto de Ciências da Saúde, Federal University of Bahia, Salvador, Bahia, Brazil

${ }^{\mathrm{d}}$ University of Camilo Castelo Branco, São José dos Campos, São Paulo, Brazil

${ }^{\mathrm{e}}$ National Institute of Optics and Photonics, Physics Institute, São Carlos, São Paulo, Brazil

12:45 ANTIMICROBIAL PHOTODYNAMIC THERAPY IN CHRONIC OSTEOMYELITIS INDUCED BY STAPHYLOCOCCUS AUREUS: AN IN VITRO AND IN VIVO STUDY

J.A. Reis Júnior, P.N. Assis, G.M. Paraguassú, I.C.V. DeCastro, R.F. Trindade, A.M.C Marques, P.F. Almeida, A.L.B. Pinheiro

Odontologia UFBA, Bahia Salvador, Brazil

13:00 POSSIBLE IMPLICATIONS OF

«BALANCE-THERAPY»: PROLIFERATION

OF NORMAL AND TUMOR CELLS IN

THE PRESENCE OF SERUM OF

PATIENTS WITH BREAST CARCINOMA

AFTER PHOTOTHERAPY WITH VISIBLE

AND NEAR INFRARED LIGHT

${ }_{\text {A.A. } \text { Zimin }^{1}}{ }^{1}$, N.A. Zhevago ${ }^{2}$, K.A. Samoilova ${ }^{2}$

${ }^{1}$ Russian Research Center of Radiology and Surgical Technologies, St. Petersburg

${ }^{2}$ Institute of Cytology, Russian Academy of Sciences, St. Petersburg, Russia 


\section{3:15 PREVENTION OF POSTRADIATION DAMAGES} IN PATIENTS WITH PROSTATIC CANCER WITH LOW POWER PHOTOTHERAPY AND THEIR SURVIVAL ANALYSIS FROM THE POINT OF VIEW OF «BALANCE-THERAPY»

A.A. Zimin ${ }^{1}$, G.M. Zharinov ${ }^{1}$, K.A. Samoilova ${ }^{2}$, N.Yu. Neklasova ${ }^{1}$, L.A. Volodina ${ }^{1}$

${ }^{1}$ Russian Research Center of Radiology and Surgical Technologies, St. Petersburg, Russia

${ }^{2}$ Institute of Cytology, Russian Academy of Sciences, St. Petersburg, Russia

13:30 LIGHT LUNCH

LASER BIOMODULATION - 2

Room A - November $4^{\text {th }}, 2011$

Chairmen: J. Anders, G.D. Baxter, N. Salanski

15:00 EVALUATION OF LASER

PHOTOBIOMODULATION ON HEALING

OF BONE DEFECTS GRAFTED WITH

BOVINE BONE IN DIABETIC RATS

GM Paraguassúa, MDMC Lino ${ }^{\mathrm{a}}$, FB Carvalho ${ }^{\mathrm{a}}$,

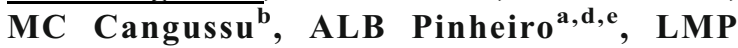
Ramalho ${ }^{\text {a,c }}$

${ }^{a}$ Center of Biophotonics, School of Dentistry, Federal University of Bahia, Salvador, Bahia, Brazil ${ }^{\mathrm{b}}$ Oral Epidemiology and Public Health, School of Dentistry, Federal Univ. of Bahia, Salvador, BA, Brazil ${ }^{c}$ Laboratory of Surgical Pathology, School of Dentistry, Federal University of Bahia, Salvador, Bahia, Brazil

${ }^{\mathrm{d}}$ Univ. of Camilo Castelo Branco, São José dos Campos, São Paulo, Brazil

${ }^{\mathrm{e} N a t i o n a l ~ I n s t . ~ o f ~ O p t i c s ~ a n d ~ P h o t o n i c s, ~ P h y s . ~ I n s t, ~ S . ~}$ Carlos, São Paulo, Brazil

15:15 PROFILING OF GENES CENTRAL TO WOUND HEALING FOLLOWING LOW INTENSITY LASER IRRADIATION

N. Houreld, H. Abrahamse

Laser Research Centre, University of Johannesburg

15:30 IS THERE REALLY A THRESHOLD OBSERVED

IN LLLT? IS THERE A THRESHOLD BASED ON PHYSICAL PROPERTIES?

\section{Hans A. Romberg}

Dr. Hans Romberg Medizintechnik, Schillerstr. 44, D 76297 Stutensee, Germany; and I3M, Unter der Schanz 2,D 69117 Heidelberg, Germany
15:45 DIFFERENTIAL RESPONSE OF CENTRAL AND PERIPHERAL NEURONS TO LIGHT IN AN IN VITRO DIABETIC MODEL

J. Anders, Xingjia Wu, Stephanie Alberico, Helina Moges, Jason Smith ${ }^{2}$ and Brian Pryor ${ }^{2}$

${ }^{1}$ Uniformed Services University Bethesda, USA

${ }^{2}$ Lite Cure LLC

16:00 DIABETIC DISTAL SYMMETRIC

POLYNEUROPATHY: EFFECT OF LOW

INTENSITY LASER THERAPY

Khamseh M., MD ${ }^{1}$, Kazemikho N., MD. Ph.D. St. $^{2}$, Aghili R. MD ${ }^{1}$, Forough B. MD $^{3}$, Lajevardi M. $^{4}$, Dabbaghian F.H., $\mathrm{MD}^{5}$ Gooshegir A., $\mathrm{MD}^{5}$, Malek M., MD $^{6}$

${ }^{1}$ Institute of Metabolism and Endocrinology, University of Medical Science,Tehran, Iran

${ }^{2}$ Dept of Genetic, Medical Faculty, Tehran University

${ }^{3}$ Dept of Physical Medicine and Rehabilitation, Firoozgar hospital, Tehran Univ. of Medical Sciences, Tehran, Iran

${ }^{4}$ Department of Laser, Milad Hospital, Tehran, Iran

${ }^{5}$ Res. Inst. for Islamic and Complementary Medicine, Iran Univ.

${ }^{6}$ Mojtaba Malek: Institute of Metabolism and Endocrinology, Univ. of Medical Science,Tehran, Iran

16:15 A SIMPLE MODEL FOR THE BIPHASIC DOSE-EFFECT RELATION OBSERVED IN LLLT

Hans A. Romberg, M.D.

Dr. Hans Romberg Medizintechnik, Schillerstr. 44, D 76297 Stutensee, Germany; and I3M, Unter der Schanz 2, D 69117 Heidelberg, Germany

16:30 COFFEE-BREAK

16:45 INDUCTION OF AUTOLOGOUS BONE MARROW STEM CELLS BY LOW ENERGY LASER THERAPY HAS BENEFICIAL EFFECTS ON KIDNEY POST ISCHEMIA-REPERFUSION INJURY IN THE RAT

Hana Tuby, Lidya Maltz, and Uri Oron

Department of Zoology, The George S. Wise Faculty of Life Sciences, Tel-Aviv

University, Tel-Aviv, 69978, Israel

17:00 PAIN CONTROL WITH LLL-THERAPY

Herold Manfred, MD

Ao. Univ.-Prof. DDr. Medizinische Universität Innsbruck Universitätsklinik für Innere Medizin 1 Rheumaambulanz \& Rheumalabor Anichstrasse 35 A-6020 Innsbruck 
17:15 NON SURGICAL LASER IN REGENERATIVE MEDICINE: THERAPY OF TRAUMATIC CENTRAL NERVOUS SYSTEM INJURIES

L. Longo, MD

Siena University, Institute Laser Medicine, Firenze

17:30 - ROUND TABLE WITH SCI PATIENTS

TRENDS IN BASIC AND APPLIED RESEARCH IN LASER BIOMEDICINE

Room B - November $4^{\text {th }}, 2011$

Chairmen: S. Gonchukov, H. Jelinkova, A. Vaitkuviene

15:00 PERIODONTITIS DIAGNOSTICS ON THE BASIS OF SALIVA RAMAN SPECTROSCOPY

S.A. Gonchukov and A.V. Sukhinina

Moscow State Engineering Physics Institute, Moscow, Russia gonchukov@mephi.ru

15:15 LASER MONITORING OF RESPIRATION ACTIVITY IN PRETERM INFANTS: MONITORING OF PECULIAR EVENTS.

L. Scalise, Eng., Paolo Marchionni, Ilaria Ercoli, Enrico Primo Tomasini

Dipartimento di Ingegneria Industriale e Scienze Matematiche, Università Politecnica delle Marche Ancona University, Italy

15:30 THE MULTISPECTRAL VISUALIZATION OF GLIAL BRAIN TUMORS CONTAINING PPIX IN DIFFUSE AND LASER-INDUCED FLUORESCENT LIGHT

Tatiana Savelieva Vavilova, M.V. Loschenov, K.G. Linkov

Prokhorov General Physics Institute of the Russian Academy of Sciences (GPI RAS)

15:45 ASSESSMENT OF FLUORESCENCE SPECTRA OF DRIED SALINE USED TO UTERINE HYDROSONOGRAPHY

V. Gegzna ${ }^{1,2}$, P. Sladkevicius ${ }^{3}$, A. Vaitkuviene ${ }^{1}$, J. Vaitkus ${ }^{1}$

${ }^{1}$ Institute of Applied Research, Vilnius University, Vilnius, Lithuania

${ }^{2}$ Faculty of Natural Sciences, Vilnius University, Vilnius, Lithuania

${ }^{3}$ Dept of Obstetrics and Gynecology, Skanes University Hospital, Malmo, Sweden
16:00 PHENOTHIAZINES MOLECULAR MODIFICATIONS AT INTERACTION WITH LASER BEAMS

M.L. Pascu ${ }^{1 *}$, A. Smarandache ${ }^{1}$, J. Kristiansen ${ }^{2}$, A. Militaru ${ }^{1}$, V. Nastasa ${ }^{1}$, L. Amaral $^{3}$

${ }^{1}$ National Institute for Laser, Plasma and Radiation Physics, Magurele, Romania

${ }^{2}$ Unit of Mycobacteriology and UPMM, Instituto de Higiene e Medicina Tropical, Universidade Nova de Lisboa, Lisbon, Portugal

${ }^{3}$ Department of Clinical Microbiology, Sønderborg Sygehus, Denmark

16:15 LASER SOLIDIFICATION OF INJECTABLE SCAFFOLDS

Evgeny Antonov, V.N.Bagratashvili, I.A. Borschenko, B.N. Khlebtsov, N.G. Khlebtsov, S.A. Minaeva, V.K. Popov, A.V. Popova Institute of Laser and Information Technologies, Russian Academy of Sciences, Troitsk

16:30 EXPANSIVE PROMOTION OF SCIENTIFIC RESEARCH

V. Navratil, L. Navratil

Czech Technical University in Prague, Faculty of Biomedical Engineering, Dept of Medical and Humanities. Kladno, Czech Republic

16:45 MINIMIZING RISK AND ENSURING

QUALITY THROUGH COMPLIANCE WITH

INTERNATIONAL SAFETY STANDARDS

Penny J. Smalley, R.N., CMLSO

Technology Concepts International

Chicago, Illinois, USA

19:15 OPEN CEREMONY WITH WELCOME COCKTAIL AND LEADING LECTURE

Provincia di Firenze, Palazzo Medici-Riccardi, Sala Luca Giordano, Via Cavour, 1 Firenze

LASER DENTISTRY - 1

Room A $-5^{\text {th }}$ November, 2011

Chairmen: C. Fornaini, G. Lynn-Powell, A.L.B. Pinheiro

9:00 SURGICAL TREATMENT OF ORAL LESIONS WITH THE CARBON DIOXIDE LASER

Antonio Pinheiro, Gilberth Tadeu dos Santos Aciole, Jouber Mateus dos Santos Aciole, Luiz Guilherme Pinheiro Soares, Nicole Ribeiro Silva Santos, Jean Nunes dos Santos

Center of Biophotonics, School of Dentistry, Federal Univ Bahia 
9:15 TM: YAP MICROCHIP LASER FOR DEBONDING CERAMIC ORTHODONTIC BRACKETS - BOND STRENGTHS MEASUREMENT

Tatjana Dostalova, Helena Jelinkova, Jan Sulc, Petr Koranda, Michal Nemec

Charles University, 2nd Medical Faculty, Prague, Czech Republic; CVUT FJFI, Prague, Czech Republic; Sendai National College of Technology, Sendai, Japan

9:30 COMPARED ANALYSIS OF THE SHADE, TEMPERATURE AND HP CONCENTRATION DURING DENTAL BLEACHING BY USING TWO DIFFERENT WAVELENGHTS: A PRELIMINARY IN VITRO STUDY WITH KTP AND DIODE LASER

Fornaini C, Lagori G, Merigo E, Meleti M, Manfredi E, Vescovi P

European Master Degree in Oral Laser Applications, Dental School, Faculty of Medicine, University of Parma (Italy)

9:45 915 AND 1064 NM COMBINED DIODE LASER IN ORAL SOFT TISSUES SURGERY: IN VITRO AND CLINICAL STUDY

Fornaini C, Rocca JP

Faculty of Dentistry, University of Nice-Sophia Antipolis (France)

10:00 LASERS IN ORAL SOFT TISSUE SURGERY: WHICH WAVELENGTH TO CHOOSE?

Seif $\mathbf{B}^{1}$, Augros $\mathbf{C}^{2}$, Raybaud $\mathbf{H}^{3}$, Fornaini $\mathbf{C}^{2}$, Rocca JP ${ }^{2,3}$

${ }^{1}$ European Master Degree Oral Laser ApplicationUniv. of Nice Sophia Antipolis-France

${ }^{2}$ TELEO laboratory, Univ. of Nice Sophia Antipolis, France

${ }^{3}$ St Roch Univ. Hosp. Nice, France

10:15 EFFICACY OF ER,CR:YSGG RADIAL FIRING TIPS ON THE LASER ASSISTED ENDODONTIC TREATMENT - BLIND RANDOMIZED CLINICAL TRIAL

M. Martins, M. Carvalho' ${ }^{1}$,J. Capelas ${ }^{1}$, I. Vaz $^{1}$, M. A. Martins ${ }^{2}$, N. Gutknecht ${ }^{3}$

${ }^{1}$ Faculdade de Medicina Dentária, Oporto University

${ }^{2}$ UCP-CRB University

${ }^{3}$ RWTH Academy, Aachen University

10:30 COFFEE-BREAK
LASER DENTISTRY and ENT - 2

Room A $-5^{\text {th }}$ November, 2011

Chairmen: A. Baruchin, T. Dostalova, B. Palmieri

10:45 OSTEONECROSIS OF THE JAWS AND BISPHOSPHONATES: LASER TREATMENT AND LONG TERM FOLLOW-UP IN 180 PATIENTS

Paolo Vescovi ${ }^{1}$, Elisabetta Merigo ${ }^{1 *}$, Maddalena Manfredi $^{1}$, Marco Meleti ${ }^{1}$, Carlo Fornaini ${ }^{1}$, Rebecca Guidotti ${ }^{1}$, Amin Sarraj ${ }^{1}$, Giovanni Mergoni $^{1}$, Jean-Paul Rocca ${ }^{2}$, Samir Nammour ${ }^{3}$

${ }^{1}$ Master Europeo "Laser in Odontostomatologia" European Master Degree in Oral Laser Applications EMDOLA - Università di Parma (Direttore: Prof. Paolo Vescovi)

${ }^{2}$ Univ. of Nice-Sophia Antipolis (France), Dentistry Fac., Teleo Lab.

${ }^{3}$ EMDOLA (European Master Degree on Oral Laser Applications) General Coordinator

11:00 LLLT WITH ND:YAG LASER IN DENTAL EXTRACTIONS IN RATS UNDER ZOLEDRONIC ACID AND DEXAMETHASONE

ADMINISTRATION. PILOT STUDY

Vescovi $\mathbf{P}^{1}$, Merigo $\mathbf{E}^{1^{*}}$, Corradi $\mathbf{D}^{2}$, Maestri $\mathbf{R}^{2}$, Manfredi $\mathbf{M}^{\mathbf{1}}$, Meleti $\mathbf{M}^{\mathbf{1}}$, Fornaini $C^{\mathbf{1}}$, Nammour $\mathbf{S}^{\mathbf{3}}$

${ }^{1}$ Master Europeo "Laser in Odontostomatologia" European Master Degree in Oral Laser Applications EMDOLA - (Direttore: Prof. P. Vescovi) - Univ. di Parma - Parma, I

${ }^{2}$ Dipartimento di Patologia e Medicina di Laboratorio Sezione di Anatomia patologica - Università di Parma, Parma, Italy

${ }^{3}$ EMDOLA (European Master Degree on Oral Laser Applications) General Coordinator

11:30 LASER AND SPECIAL CARE DENTISTRY: A NEW PERSPECTIVE

A. Oppici ${ }^{1}$, F. Clini ${ }^{1}$, C. Fornaini $^{1}$, M. Fontana ${ }^{1}$, L. Cella, E. Merigo ${ }^{1}$

${ }^{1}$ U.O.S. Odontostomatology and Maxillo-facial Surgery Unit "Special cares and Special Projects" Guglielmo da Saliceto"Hospital - Piacenza - Italia

11:45 LASER IN DENTISTRY. BIOSTIMULATION AND SURGERY

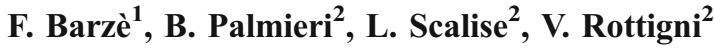

${ }^{1}$ Professional man, Italy

${ }^{2}$ Dept of General Surgery and Surgical Specialties, Univ. of Modena and Reggio Emilia Med School, Surgical Clinic, Modena, Italy

${ }^{3}$ Dipartimento di Ingegneria Industriale e Scienze Matematiche, Università Politecnica delle Marche - Ancona University, Italy 
12:00 PRELIMINARY STUDY ON RADIO-CHEMIOINDUCED ORAL MUCOSITIS AND LOW LEVEL LASER THERAPY

Matteo Fontana ${ }^{1 *}$, Elisabetta Merigo ${ }^{1-2}$, Carlo Fornaini $^{2}$, Fabio Clini ${ }^{1}$, Luigi Cella ${ }^{1}$, Paolo Vescovi $^{2}$, Aldo Oppici ${ }^{1}$

${ }^{1}$ U.O.S.D. di Odontostomatologia e Chirurgia Maxillo-Facciale - Ospedale "Guglielmo da Saliceto" - Piacenza - Italia

${ }^{2}$ Master Europeo "Laser in Odontostomatologia" European Master Degree in Oral Laser Applications EMDOLA - Università di Parma (Direttore: Prof. Paolo Vescovi) - Univ. di Parma -Italia

12:15 Nd:YAG LASER BLOODLESS TONSILLECTOMY BY FIBEROPTIC DOPPLER COUPLED HANDPIECE BEAM DELIVERY

\section{B. Palmieri ${ }^{1}$, V. Rottigni ${ }^{1}$}

${ }^{1}$ Dept of General Surg. and Surgical Specialties, Univ. of Modena and Reggio Emilia Medical School, Surgical Clinic, Modena, Italy

12:30 LASER UVULOPALATOPHARYNGEOPLASTY VERSUS LASER PARTIAL MUCOSAL PALATAL EXCISION AS SURGERICAL TREATMENT OF SIMPLE AND OBSTRUCTIVE SNORING

\section{Khaled Mohamed Bofares}

Associate Professor Otorhinolaryngology

Department Omar Almoukhtar University, Elbyda, Libya

12:45 DIFFERENT VARIETIES OF LASER

SURGICAL PROCEDURES FOR

MANAGEMENT OF SNORING

PATIENTS WITH UVULAR ABNORMALITIES

Khaled Mohamed Bofares

Associate Professor Otorhinolaryngology

Department Omar Almoukhtar University, Elbyda, Libya

13:00 MILESTONES IN THE EVOLUTION OF ENDOSCOPY: A SHORT HISTORY WITH SPECIAL EMPHASIS ON SIALOENDOSCOPY

Oded Nahlieli DMD ${ }^{1}$, Ohad Baruchin $\mathrm{MD}^{2}$ and Abe M.Baruchin MD $^{3}$

${ }^{1}$ Professor and chairman, Dept of Oral \& Maxillofacial Surgery, Barzilai University Medical Center Ashkelon, Israel

${ }^{2}$ Dept of $\mathrm{Ob} / \mathrm{Gyn}$, Assaf Harofeh University Medical Center, Zerifin, Israel

${ }^{3}$ Professor, Chief of the Laser Unit, University Barzilai Medical Center Ashkelon, Israel

\section{LASER NEUROSURGERY}

Room B - November 5th, 2010

Chairmen: J. Chiu, A. Lauto, M. Stark

09:00 INNOVATIVE GRID POSITIONING SYSTEM (GPS) FOR ENDOSCOPIC LASER

TRANSFORAMINAL MICRODECOMPRESSIVE LUMBAR DISC SURGERY IN THE MORBID OBESE

J. Chiu, MD

California Spine Institute, Laser Neurospine Surgery

Thousand Oaks - USA

chiu@spinecenter.com

09:15 LASER ENDOSCOPIC ANTERIOR CERVICAL DISCECTOMY/FORAMINOPLASTY WITH INTRAOPERATIVE NEUROPHYSIOLOGICAL MONITORING (IOM)

\section{J. Chiu, MD, PhD}

California Spine Institute, Laser Neurospine Surgery, Thousand Oaks, USA

09:30 LASER MINIMALLY INVASIVE SPINE

SURGERY (MISS): A SURGEON'S PERSPECTIVE

ON TECHNOLOGICAL CONVERGENCE AND DIGITAL OR CONTROL SYSTEM

\section{J. Chiu, MD}

California Spine Institute, Laser Neurospine Surgery Thousand Oaks - USA

09:45 LASER THORACIC ENDOSCOPIC MICRODISCECTOMY WITH GPS SYSTEM

\section{J. Chiu, MD, PhD}

California Spine Inst, Laser Neurospine Surg, Thousand Oaks, USA

10:00 SACROILIAC JOINT PAIN SYNDROME: ANATOMY DIAGNOSIS AND TREATMENT SURGICAL LASER THERMONEURECTOMY

\section{J. Chiu, MD}

California Spine Institute, Laser Neurospine Surgery Thousand Oaks - USA

10:15 PERCUTANEOUS LASER LUMBAR INTERVERTEBRAL DISC-DECOMPRESSION

Gunaras Terbetas, A. Vaitkuviene

Clinics of Neurology and Neurosurgery, Vilnius University Hospital, Lithuania

10:30 FABRICATION OF ADHESIVE BIOGLASS/

POLYESTER SCAFFOLDS FOR SPINAL DISK DEFECTS

$\underline{\text { A. Lauto }}^{1}$, M. Mnatsakanyan ${ }^{1}$, S. Piller ${ }^{1}$, D. Mawad ${ }^{2}$, L. Longo ${ }^{3}$, P. Boughton ${ }^{4}$

${ }^{1}$ University of Western Sydney

${ }^{2}$ University of Wollongong

${ }^{3}$ University of Siena

${ }^{4}$ University of New South Wales 
November 5th, 2011

13:15 - TALK POSTER SESSION

Chairmen: M. Postiglione, P. Smalley

INTERFERENTIAL LASER THERAPY IN THE RELIEF OF PAIN IN THE CARPAL TUNNEL SYNDROME. A PILOT STUDY

Ramon Montes-Molina, Maria Elena MartinezRodriguez, Almudena Prieto-Baquero, Blanca Palomino-Aguado, Susana Lopez-Serrano, Ignacio Regidor-Bailly-Bailliere, Berta Collantes-Panero, Rosa Aliaga-Casto, Maria Jesus GutierrezGarcia, Fidel Martinez-Ruiz

Hosp. Univ Ramón y Cajal.IRYCIS.Unit of Clinical Electrotherapy, Department of Physical Medicine and Rehabilitation. Department of Neurology. Unit of Occupational Therapy. Department Orthopaedic Surgery, Madrid, Spain

GaAlAs LASER DIODE LASER -

TEMPOROMANDIBULAR JOINT

REHABILITATION

P. Hlinakova, T. Dostalova, V. Navratil, E. Blazkova, L. Navratil

Charles University $2^{\text {nd }}$ Medical Faculty, Department of Paediatric Stomatology, Prague, Czech Republic; Charles University $1^{\text {st }}$ Faculty of Medicine, Institute of Biophysics and Informatics, Prague, Czech Republic; CVUT - Faculty of Biomedical Engineering, Kladno, Czech Republic; THERAP-THILIA, Department of Physiotherapy, Prague, Czech Republic EVALUATION OF LASER PHOTOBIOMODULATION ON HEALING OF BONE DEFECTS GRAFTED WITH BOVINE BONE IN DIABETIC RATS

GM Paraguassú, MDMC Lino, FB Carvalho, MC Cangussu, ALB Pinheiro, LMP Ramalho School of Dentistry, Federal Univ. of Bahia, Faculdade de Odontologia, Centro de laser- Salvador Bahia
OR LED PHOTOBIOMODULATION ON

HYPOTHYROID RATS OF CUTANEOUS WOUND HEALING: A MORPHOMETRIC STUDY

De Castro, I.C.V.; Paraguassú, G.M.; Reis Júnior, J.A.; Xavier, F.C.A.; Rodriguez,T.T.; Ramalho, M.J.P.; Pinheiro, A.L.B.; Ramalho, L.M.P. Federal University of Bahia, Faculdade de Odontologia, Salvador, Brazil
5 HEMANGIOMA TREATMENT EFFECT OF PDL, ALEXANDRITE, ER: YAG AND CO2 LASERS Eva Remlova ${ }^{1}$, Tatjana Dostalova ${ }^{2}$, Helena Jelinkova ${ }^{3}$, Jana Vranova ${ }^{3}$, Leos Navratil ${ }^{4}$, Jozef Rosina ${ }^{4}$

${ }^{1}$ AVE LASER CENTRUM, Olomouc, Czech Republic

${ }^{2}$ Charles University, 2nd Medical Faculty, Department of Paediatric Stomatology, Prague

${ }^{3}$ Czech Technical University in Prague, Faculty of Nuclear Sciences and Physical Engineering, Prague ${ }^{4}$ Czech Technical University in Prague, Faculty of Biomedical Engineering, Kladno, Czech Republic RAMAN IMAGING FOR THE IDENTIFICATION OF BREAST CANCER CELLS

J.L. Gonzales ${ }^{1}$, G.H. Luévano-Colmenero ${ }^{2}$, J. Vargas-Mancilla ${ }^{2}$, I.A. Arana-Zamora ${ }^{2}$, J.C. Martínez-Espinosa ${ }^{2}$

${ }^{1}$ Centro Universitario de los Lagos, Universidad de Guadalajara

${ }^{2}$ Instituto Mexicano del Seguro Social

LASERTHERAPY IN POSTPARTUM VAGINAL ATROPHY

\section{Daniela Brinzan, Lucian Paiusan}

Hospital of Obstetrics and Gynecology Arad, Romania

8 LOW LEVEL LASER IRRADIATION AND

CYTOKINES: REVIEW STUDY

Julia Efremova, Vaclav Navratil

Czech Technical University in Prague, Faculty of Biomedical Engineering Biomedical and Clinical Technology

13:30 - LIGHT-LUNCH

\section{LASER SKIN MEDICINE AND SURGERY}

Room A - November $5^{\text {th }}, 2011$

Chairmen: K. Khatri, T. Ohshiro, K. Russe-Wilflingseder

\section{4:45 PLACEBO CONTROLLED, PROSPECTIVELY} RANDOMIZED, DOUBLE-BLINDED STUDY FOR THE INVESTIGATION OF THE EFFECTIVENESS AND SAFETY OF THE ACOUSTIC WAVE THERAPY $\left(\mathrm{AWT}^{\circledR}\right)$ FOR THE CELLULITE TREATMENT

Katharina Russe-Wilflingseder ${ }^{1}$, Elisabeth Russe ${ }^{1}$, Monika Drmic ${ }^{1}$, Johannes C. Vester ${ }^{2}$, Gerd Haller ${ }^{3}$, Pavel Novak ${ }^{3}$, Alexander Krotz ${ }^{3}$

${ }^{1}$ Plastische Chirurgie und Laserzentrum Innsbruck, Austria

${ }^{2}$ idv, Gauting, Germany

${ }^{3}$ Storz Medical, Tägerwilen, Switzerland 
15:00 A NEW MINIMAL INVASIVE LASER-ASSISTED TECHNOLOGY TO TREAT SKIN LAXITY, FAT AND CELLULITE

Katharina Russe-Wilflingseder, Manfred Herold, Elisabeth Russe

Plastische Chirurgie und Laserzentrum, Innsbruck, Austria

15:15 SYRINGE-ASSISTED NECK LIPOSUCTION

ALONE AND IN COMBINATION WITH LOW

INTENSITY LASER LIPOLYSIS FOR SKIN TIGHTENING

Misbah Khan ${ }^{1}$ MD, Tiffany Turner ${ }^{2}$ RN, Murad Alam $^{2}$ MD

${ }^{1}$ Weill Cornell Medical College, New York, USA

${ }^{2}$ Northwestern University, New York, USA

15:30 LASER TX OF SCARS/AN OVERVIEW AND

PRESENT STATUS/DIFFERENT TX OPTIONS

WHAT TO DO WHEN/PROS AND CONS

Katharina Russe-Wilflingseder, Elisabeth Russe

Plastische Chirurgie und Laserzentrum, Innsbruck, Austria

15:45 LASER SCAR REVISION

Khalil A. Khatri, M.D.

New England Institute of Laser Research

Skin \& Laser Surgery Center of New England Boston, USA

16:00 FRAXELATED RADIOFREQUENCY DEVICE

FOR ACNE SCARS

Babar K. Rao ${ }^{1}$, MD, Sairah Khokher ${ }^{2}$, MD

${ }^{1}$ Associate Professor and Chair at Department of Dermatology, Robert Wood Johnson Medical School

${ }^{2}$ Fellow at Dept of Dermatology, R. Wood Johnson Med. School

16:15 THE COMBINED SURGICAL AND LASER TREATMENT OF THE GIANT PORT-WINE STAIN MALFORMATION - CASE REPORT

P. Drozdowski, MD, Siewiera Ireneusz, M.D., PhD, Wójcicki Piotr, M.D., PhD.

Dept of Plastic and Reconstructive Surgery in Polanica Zdrój, Wrocław Medical University

16:30 - COFFEE-BREAK
16:45 LONG TERM EVALUATION OF PDL LASER IN DERMATOLOGY

Eva Remlova ${ }^{1}$, Tatjana Dostalová ${ }^{2}$, Helena Jelínková $^{3}$, Jana Vránová ${ }^{3}$, Leoš Navrátil ${ }^{4}$, Josef Rosina $^{4}$

${ }^{1}$ AVE LASER CENTRUM, Olomouc, Czech Republic

${ }^{2}$ Charles Univ, $2^{\text {nd }}$ Medical Faculty, Department of Paediatric Stomatology, Prague, Czech Republic

${ }^{3}$ Czech Technical Univ. in Prague, Faculty of Nuclear Sciences and Physical Engineering, Prague

${ }^{4}$ Czech Technical Univ. in Prague, Faculty of Biomedical Engineering, Kladno, Czech Rep.

17:00 MELASMA: A COMMON PROBLEM IN SOUTH EAST ASIA

Naqiba Munshi, MD

Elements MediSpa, Karachi, Pakistan naqibamunshi@hotmail.com

17:15 LASER TREATMENT OF PATIENTS WITH

DARKER SKIN: SPECIAL CONSIDERATIONS

Khalil A. Khatri, MD

New England Institute of Laser Research, Skin \& Laser Surgery Center of New England - Boston, USA

17:30 TREATMENT OF 638 JAPANESE FEMALE INFERTILITY PATIENTS WITH GAALAS DIODE LASER

Toshio Ohshiro, Yuki Taniguchi, Takafumi Ohshiro, Katsumi Sasaki

Ohshiro Clinic, Japan Medical Laser Laboratory, Plastic and Reconstructive Surgery - Tokyo, Japan

17:45 IALMS and IPTA General Assembly

20:30 - GALA DINNER WITH MUSIC, CLOSURE CEREMONY, AWARDS ASSIGNATION 


\section{INVITATION}

The annual Congress of the International Academy Laser Medicine and Surgery, called Laser Florence 2011, would like to open a window on four different sector of laser use on human body: skin, nervous system, teeth and cellular level.

In these sectors laser use allowed diagnosis and treatment of different lesions, better than traditional procedures. Advantages, limits and controversies will be discussed by pioneers and opinion leaders of this matter, together young researchers and doctors. As usual this mix will product new data immediately available for practical use.

A special session will be dedicated to role of laser beams and light in Energetic Medicine, called now Quantum Medicine and Regenerative Medicine.

The International Academy ensures a high quality of the lectures and posters presented. The accepted abstracts are published in the official journal of the IALMS, Laser in Medical Science, published by Springer Publisher, London. The Proceedings of the Conference will be published immediately after the event, on paper and on line.

In according with the WFSLMS - World Federation Societies of Laser Medicine and Surgery, the IALMS is presenting an International Master on Laser Medicine and Surgery, with duration of 1 year. Laser Florence will be the annual adjournment for the International Medical Laser Specialists.

The aim of Laser Florence organisers is particular: to establish an outstanding interaction between the delegates in a unique location and an unforgettable atmosphere where friendship, intelligence and scientific know-how are blended.

Several awards are available for the presenters of the best papers and posters and the recipients will be invited to participate in the next conference of Laser Florence.

To fully understand the importance of Laser Florence, there is only one way, coming here!

Looking forward to seeing you in Florence

Best regards

Leonardo Longo, M.D. 
REGENERATIVE PHOTONIC THERAPY: REVIEW Natasha Salansky and Norman Salansky

Millennium Health Institute

1600 Steeles Ave. West, Suite 21

Concord, Ontario L4K 4 M2 - Canada

A large body of basic research suggests that specific forms of monochromatic light can induce phenomena vital for wound and tissue healing and regeneration. Thorough analysis of in vitro and animal studies shows that different photoinduced phenomena (e.g., ATP synthesis or fibroblast proliferation enhancement) require different sets of optical parameters that should be delivered within the injured/ pathological tissue providing required 3-dimentional photon distributions - so called Therapeutic Optical Windows (TOWs). In most cases, it is impossible to deliver required TOWs using a single photonic source as its optical parameters may not accommodate to all the requirements. We present a novel approach of regenerative photonic therapy (RPT) for tissue healing and regeneration that includes treating injured/pathological tissues using multiple photonic sources that have fully adjustable optical parameters and can deliver required TOWs to the tissue. Clinical protocols of RPT are diversified and adjusted in accordance to pathological conditions of tissue, phases of tissue healing, and patient's condition. Review of clinical protocols for effective therapy is presented. Clinical protocols of RPT were tested in 10 clinical studies for acute and chronic pain, rehabilitation after plastic surgery and sports injuries. In these clinical studies substantial immediate and mid-term pain relief was consistently demonstrated accompanied by function improvement and normalization of impaired nerve conduction in patients with chronic CTS. Clinical protocols of RPT for facial surgery or sports injuries resulted in 2-5fold acceleration of recovery with pain and swelling resolution after 1-3 treatments. 3.4-fold acceleration of healing was observed in a double blind study on patients with chronic leg ulcers.

\section{WHICH LASER THERAPY COULD BE CALLED “QUANTUM MEDICINE"? A PHYSICIST'S VIEW}

\section{Hans A. Romberg, MD}

Dr. Hans Romberg Medizintechnik, Schillerstr . 44, D76297 Stutensee, Germany; and 3 M, Unter der Schanz 2, D 69117 Heidelberg, Germany

Laser light is a macroscopic quantum phenomenon. Laser light is used for therapy, but are the specific quantum properties crucial for the medical outcome? Coherence is the best known laser quantum property, but the necessity of coherence for medical application has been as well claimed, as questioned. It is used in optical coherence tomography, where the working depth is limited to less than $1 \mathrm{~mm}$ due to lack of coherence in backscattered light from deeper layers. Thus, the initial coherence is lost quite soon. However, along with the coherence other effects may appear, like local polarization, or locally inhomogeneous intensities. These might lead to additional effects, as e.g. very small temperature changes over membranes, thus leading to small changes in electrical and chemical local properties, thus to biochemical effects.

But there are further technical differences between laser, and non-laser light sources, leading to strong differences in spectral width, wavelengths used, but also the possibility to focus on a small spot or into a light guide, and the price of therapeutical devices. These differences might be more important for the choice of a laser, or a non-laser, therapeutical device. Due to the basic physical properties it is very hard to perform good studies to compare laser, and non-laser, therapeutical outcome in experiments using comparable light properties.

\section{LASER RADIATION INTERACTION WITH FLUOROFORES IN MICRO-/NANO-DROPLETS OF SOLUTIONS}

M.L. Pascu, I.R. Andrei, V. Nastasa, M. Boni, G.V. Popescu

National Institute for Laser, Plasma and Radiation Physics, Magurele, Romania

mihai.pascu@inflpr.ro

The micro- and nanodroplets may be a new vector used to transport medicines to tissues or, more specifically, to targets which might be tumours or bacteria that developed multiple drug resistance (MDR). The generation of droplets, of volumes between $3 \mu \mathrm{l}$ to $4.5 \mu \mathrm{l}$ containing distilled water or solutions of Rhodamine $6 \mathrm{G}(\mathrm{R} 6 \mathrm{G})$ at $10^{-3} \mathrm{M}$ in distilled water, in suspended position, is reported. The resonant and unresonant interaction of the droplets with laser beams is studied and results are shown for several levels of laser beam energy $(0.25 \mathrm{~mJ}, 0.4 \mathrm{~mJ}, 0.7 \mathrm{~mJ}$ and $1.0 \mathrm{~mJ}$ ), various microdroplets dimensions and different positions of the laser beam impact point on the microdroplets surfaces or within their volume.

The microdroplets are generated in hanging/suspended/ pendant position using a computer controlled system.For their unresonant interaction with laser radiation, a pulsed (FTW $5 \mathrm{~ns}$, pulse reprate 10pps) beam emitted at $532 \mathrm{~nm}$ is 
used that is weakly absorbed by the distilled water (absorption coefficient $\alpha \sim 0.05 \mathrm{~m}^{-1}$ in the Beer-Lambert law). The dynamics of the microdroplets of distilled water is characterized and the conditions in which they loose material as a consequence of the impact with the laser beam are also explored. The microdroplets and the modification/ evolution of their shapes and volumes are visualised by high (10 kfs) speed recording.

The unresonant interaction leads to mechanical vibrations of the droplets at lower laser beam power levels. The characteristics of these vibrations depend on the laser beam power, the position of the focus of the laser beam with respect to the microdroplet surface/volume and the microdroplet volume (dimensions). They are due to the pressure effect of the laser radiation on the droplet. Losses of material under the form of nanodroplets that propagate with supersonic speed are shown. The effect of the laser beam on the microdroplet, at unresonant interaction, is somewhat similar with the effect of electric or magnetic fields applied on dielectric substances. Pendant droplets of smaller dimensions than the initial ones and micro/nano gas bubbles in the pendant droplets material/volume are also noticed.

At resonant interaction the effects of the laser beam on the droplet are mixed with the unresonant effects and this depends mainly on the laser beam energy/power density, the droplet's volume and the concentration of the absorbent (R6G) in the droplet. One may have laser beam absorption without inducing mechanical effects on the droplet since, after absorption, there are not available anymore enough photons to constitute the light pressure force able to act on the droplet. At higher beam energies, when there is an excess of photons one may produce in the droplet effects specific to the unresonant interaction such as: production of nanojets, generation of micro- and nano-droplets and deformation of the main droplet. If one controls the absorption of the laser beam in the droplet, which may be done by the variation of the R6G absorbent concentration, one may control the number and the characteristics of the effects produced by the light pressure on the droplet at unresonant interaction.

\section{PHOTODIAGNOSIS IN PERSONALIZED MEDICINE}

\section{A. Vaitkuviene, MD, PhD, Juozas V. Vaitkus, PhD}

Vilnius University, Lithuania

Background: Laser technique apart of surgery, biomodulation application seems to be smart tool for personalized medicine needs. We present the application of laser for new diagnostic fields at point of care.
Purpose: The spectral diagnosis of smear, washings, interstitial tissues on site for fast patient selection and treatment decision.

Material and Methods: Smear from the uterus cervix for precancer and labor advancement diagnostics, amnion fluid for pregnancy timing, uterus cavity washings for normal and abnormal endometrium, cervical, endometrial, vertebral disc biopsies were used for photodiagnosis The laser pulse ( $80 \mathrm{~ns}, 5 \mathrm{~ns}, 0,5 \mathrm{~ns}$ ) excited fluorescence spectra were recorded by spectrophotometer AvaSpec-2048TEC or OceanOptics in range from $370 \mathrm{~nm}$ to $700 \mathrm{~nm}$. The portable medical equipment was constructed: sub nanosecond (atments effects could be objective detected.

\section{THE USE OF VISIBLE LIGHT AND METAL OXIDES NANO PARTICLES FOR PATHOGENS INACTIVATION}

\section{R. Lubart, A. Gedanken and A. Lipovski}

Departments of Chemistry and Physics, Bar-Ilan University

Since the effectiveness of antibiotic treatments is decreasing due to the development of resistant strains, alternative approaches for killing microorganisms are needed. In the past we found that intense blue light could be used for bacterial eradication. The phototoxic effect correlated with the amount of reactive oxygen species (ROS) generated by the bacteria due to illumination.

In this presentation we show that the effect of light can be enhanced by introducing metal oxides nanoparticles (nps) to the bacteria prior to irradiation.

It has been found that water suspensions of metal oxides nps produce stable oxy radicals due to their high chemical activity. Moreover, we found that upon excitation of these nps with visible light an increase in ROS amount occurs. This led us to suggest combining nanoparticles with visible light irradiation for pathogen killing.

Combination of illumination with the nanoparticles $(\mathrm{ZnO}$ or $\mathrm{TiO}_{2}$ ) resulted in a marked increase in the reduction of bacterial viability to a mean reduction of $80-90 \%$ for both nanoaprticles. As a matter of fact metal oxides nps alone can be used for bacteria killing. The advantage of our approach is the use of lower concentrations of $\mathrm{np}$, combined with reduced light intensity that is less toxic to the host tissue.

To further avoid the toxicity of metaloxides nps on healthy tissue it possible to coat them on the surface of various substrates including ceramics and polymers. Recently Zinc oxide nanoparticles have been synthesized and deposited on the surface of cotton fabrics using ultrasound irradiation. Thus in the future we will try to treat infected wounds with transparent bandages coated with $\mathrm{ZnO}$ that will be loaded on the wounds prior to irradiation. 


\section{LASER PHOTOSTIMULATION OF WOUND}

HEALING IN DIABETIC MICE IS NOT CAUSED BY DIABETES-MODIFYING EFFECTS OF LASER LIGHT

Philip V. Peplow PhD ${ }^{\text {a }}$, Tzu-Yun Chunga ${ }^{\text {, G. David }}$ Baxter DPhil $^{\text {b }}$

${ }^{a}$ Department of Anatomy \& Structural Biology, and

${ }^{\mathrm{b}}$ Centre for Physiotherapy Research, School of Physiotherapy, University of Otago, Dunedin, New Zealand

Background: Healing of covered wounds in diabetic mice was stimulated by laser irradiation $660 \mathrm{~nm}, 100 \mathrm{~mW}, 20 \mathrm{~s} /$ day, 7 days, estimated dose 4.7 to $6.3 \mathrm{~J} / \mathrm{cm}^{2} /$ day. Laser light $810 \mathrm{~nm}, 1 \mathrm{~J} / \mathrm{cm}^{2} /$ session combined with a magnetic field had a hypoglycemic effect in human patients with type 1 or type 2 diabetes.

Purpose: To examine whether the stimulated healing of covered wounds in diabetic mice by laser irradiation $660 \mathrm{~nm}$ could be due to diabetes-modifying effects of laser light.

Method: Twenty-two diabetic mice were divided into two equal groups. Body weight and water intake of mice were measured daily for 7 days prior to starting the study (Day $0)$. For mice in the experimental group, the left flank was irradiated with $660 \mathrm{~nm}$ laser, $100 \mathrm{~mW}, 20 \mathrm{~s} /$ day, 7 days; for mice in the control group, the left flank was sham-treated by not switching on laser power supply. Body weight and water intake of mice were measured to Day 14. On Day 14, mice were fasted for $4 \mathrm{~h}$, anaesthetized with sodium pentobarbitone (i.p) and blood collected by cardiac puncture into heparinized tubes. Blood plasma glucose was measured by hexokinaseglucose-phosphate dehydrogenase method.

Results: No significant differences were found in body weight and water intake over 22 days between mice in the experimental group and control group. Blood plasma glucose level on day 14 was not significantly different between the two groups.

Conclusion: Irradiation of the left flank in diabetic mice with $660 \mathrm{~nm}$ laser system, 7 days does not have a significant hypoglycemic effect, and the laser-stimulated healing of wounds in diabetic mice is due to cellular and biochemical changes in the immediate wound environment.

\section{LOW LEVEL LASER IRRADIATION AND CYTOKINES: REVIEW STUDY \\ Julia Efremova, Vaclav Navratil}

Czech Technical University in Prague, Faculty of Biomedical

Engineering

Biomedical and Clinical Technology

Background: In the recent times you can find articles, reflecting the influence of laser radiation on the patholog- ical state, where an inflammation underlies. Cytokines - the most important factors; it regulate the protective reaction rights, including the reactions of inflammation and immunity. Purpose: This review summarized information about low level laser irradiation influence on cytokine expression and production.

Material and Methods: We included articles published from 2000 to 2010. PubMed, ISI Web of Science, InterScience,BioMedCentral, EBSCOhost, ScienceDirect databases were used. Search keywords were "laser therapy, laser treatment, LLLT, low level laser therapy, cytokine, tumor necrosis factor, interleukin, interferon".

Results: In most cases low level laser irradiation has an immunomodulatory effect on cytokine expression and production. This process depends on many parameters of laser, but it is not all. For example, type of experiment, degree of illumination, cell properties and other conditions, probably, can influence on study results.

Discussion and conclusion: The literature review confirmed once again the positive effect of low-intensity laser irradiation due to changes in the cytokine balance.

\section{EVALUATION OF LED PHOTOBIOMODULATION ON WOUND HEALING IN HYPOTHYROID AND EUTHYROID RATS}

GM Paraguassúa $^{a}$, FCA Xavier ${ }^{\mathrm{b}}$, TT Rodriguez ${ }^{\mathrm{c}}$, MJP Ramalho $^{c}$, ALB Pinheiro ${ }^{a, d, e}$, LMP Ramalho ${ }^{a, b}$

${ }^{\mathrm{a}}$ Center of Biophotonics, School of Dentistry, Federal University of Bahia, Salvador, Bahia, Brazil

${ }^{\mathrm{b}}$ Laboratory of Surgical Pathology, School of Dentistry, Federal University of Bahia, Salvador, Bahia, Brazil

${ }^{\mathrm{c}}$ Department of Physiology, Instituto de Ciências da Saúde, Federal University of Bahia, Salvador, Bahia, Brazil

${ }^{\mathrm{d}}$ University of Camilo Castelo Branco, São José dos Campos, São Paulo, Brazil

${ }^{e}$ National Institute of Optics and Photonics, Phys Inst, São Carlos, São Paulo

Thyroid hormone deficiency has been associated to disruption of the body's metabolism, including healing process. LED phototherapy has been shown to be effective in improving healing in many situations, but their usefulness in the improvement of hypothyroidism wound healing remains unknown. The aim of this study was to assess histologically the effect of LED (InGaAlP, $\lambda 630 \mathrm{~nm}$, $150 \mathrm{~mW}, \mathrm{CW}, \phi 0.5 \mathrm{~cm}^{2}, 24 \mathrm{~J} / \mathrm{cm}^{2}$ per session) on wounds healing in hypothyroid and euthyroid Wistar rats. Standard cutaneous wound $\left(1 \mathrm{~cm}^{2}\right)$ was created on the dorsum of 24 animals divided into four groups of 6 animals each: G1: Euthyroid; G2: Euthyroid + LED; G3: Hypothyroid; G4: Hypothyroid + LED. Hypothyroidism was induced in rats with propylthiouracil $(0,05 \mathrm{~g} / 100 \mathrm{~mL})$ administered orally 
for 4 weeks and maintained until the end of the experiment. The irradiation started immediately after surgery and was repeated every other day for 7 days. Animals were killed 8 days after surgery. The specimens were removed, routinely processed and stained with H\&E and Picrosirius. Statistical analysis was performed using the Fisher's Test and significance level was $5 \%$. The results of the present investigation showed delayed wounds healing process in hypothyroid rats characterized by incomplete reepithelialization, reduced thickness of epithelial layers and formation of disorganized collagen fibers (Fisher, $p<0,05$ ) when compared to the euthyroid group. There was histological evidence of improved amount of collagen fibers on irradiated animals (euthyroid and hypothyroid) when compared to non irradiated ones (Fisher, $p<0,05$ ). It is concluded that LED has a positive biomodulative effect on the wound healing process, even when hipothyroidism was present.

\section{ANTIMICROBIAL PHOTODYNAMIC THERAPY IN CHRONIC OSTEOMYELITIS INDUCED BY STAPHYLOCOCCUS AUREUS: AN IN VITRO AND IN VIVO STUDY}

J.A. Reis Júnior, P.N. Assis, G.M. Paraguassú, I.C.V. DeCastro, R.F. Trindade, A.M.C Marques, P.F. Almeida, A.L.B. Pinheiro

Odontologia UFBA, Bahia Salvador, Brazil

Osteomyelitis it is an acute or chronic inflammation in the marrow spaces in the superficial or cortical bone, and is closely associated with a bacterial infection. The chronic osteomyelitis represents a major health problem due to its difficult treatment and a significant morbidity caused by it. Antimicrobial photodynamic therapy (PDT) by laser is a treatment based on a cytotoxic photochemical reaction in which, a bright light produced by a laser system and an active photosensitizer absorbed by cells leads an activation that induces a series of metabolic reactions that culminates a bacterial killing. The aim of this study was to assess in vitro and in vivo by analyzing the action of microbial lethal laser photosensitization. On the in vitro study it was used laser $\left(\lambda 660 \mathrm{~nm} ; 40 \mathrm{~mW} ; \varnothing 0.4 \mathrm{~cm}^{2} ; 5\right.$ and $\left.10 \mathrm{~J} / \mathrm{cm}^{2}\right)$ and photosensitizer toluidine blue (TB) with concentrations of 5,10 and $15 \mu \mathrm{g} / \mathrm{ml}$. The concentration of $5 \mu \mathrm{g} / \mathrm{mL}$ was selected to perform the decontamination of infected bone defects caused by Staphylococcus Aureus on the tibia of rats. The results were performed by ANOVA test. On the in vitro studies all PDTs groups on the different concentrations reduced significantly $(p<0,001)$ the amount of bacteria. On the in vivo study PDT group presented a bacterial reduction of $95,4 \%(P<0,001)$. Thus, the results have shown that PDT by laser with the use of TB $(5 \mu \mathrm{g} / \mathrm{mL})$ can be an alternative of topical adjuvant treatment for individuals with chronic osteomyelitis.

\section{POSSIBLE IMPLICATIONS OF «BALANCE- THERAPY»: PROLIFERATION OF NORMAL AND TUMOR CELLS IN THE PRESENCE OF SERUM OF PATIENTS WITH BREAST CARCINOMA AFTER PHOTOTHERAPY WITH VISIBLE AND NEAR INFRARED LIGHT}

${ }_{\text {A.A. Zimin }}{ }^{1}$, N.A. Zhevago $^{2}$, K.A. Samoilova ${ }^{2}$

${ }^{1}$ Russian Research Center of Radiology and Surgical Technologies, St. Petersburg

${ }^{2}$ Institute of Cytology, Russian Academy of Sciences, St. Petersburg, Russia

Background: It is for many years that low power visible (VIS) and near infrared (nIR) radiation are used in clinical practice for stimulation of reparative processes, hemopoiesis and immunogenesis, i.e., for activation of proliferative processes at the systemic level. However, the use of phototherapeutic methods based on application of laser, photodiodes and other sources of these radiations is restrained because of apprehension of a possibility of stimulation of proliferation not only of normal, but also of transformed cells that are constantly present in the body in some particular amounts. Meanwhile, it is widely renowned fact that the tumor growth depends mainly on cell loss factor and proliferation rate, i.e. on balance of these two factors.

Purpose: To study the effect of the course of irradiations of patients with breast carcinoma (BC) at postsurgery period with VIS and nIR light on proliferating activity of primary cultures of human fibroblasts (FB) and keratinocytes (KC) and of several cultures of human tumor cells (BT-474, HBL-100, Hs578T, and A431) in the presence of blood serum of patients with BC.

Material and methods: 19 patients with BC of I-II stages before and after mastectomy participated in the trial. They were randomly divided into 2 groups. The 1st (control) group $(n=8)$ was given the conventional postoperative wound cure within 7 days after mastectomy. The $2^{\text {nd }}$ group $(n=11)$ additionally obtained daily irradiations of lumbosacral zone with polychromatic light (Swiss phototherapeutic device Bioptron-2, 480-3400 nm, $40 \mathrm{~mW} / \mathrm{cm}^{2}, 12 \mathrm{~J} / \mathrm{cm}^{2}$ ). As the target cells were used strains of BC cells (Hs578T, BT474, HBL-100) and strain of epidermoid carcinoma (A431) cells as well as 2 strains of human FB and KC. Cells were incubated in 96 -well clusters at $37^{\circ} \mathrm{C}, 5 \% \mathrm{CO}_{2}$ and $95 \%$ humidity in standard nutrient medium with the addition of $10 \%$ fetal calf serum. After 2 to 3 days of cultivation the medium was replaced with fresh medium containing serum of $\mathrm{BC}$ patients $(2.5 \%)$ taken in three 
consecutive terms: one day before and one day after mastectomy, and 7 days after postoperational phototherapeutic course. On the 3rd or 4th day of growth the number of cells was counted using a colorimetric method. The cells were fixed with $70 \%$ ethanol and stainted for 10 min with $0.1 \%$ Crystal Violet. The dye was then extracted with $10 \%$ acetic acid, and its optical density was measured using a STATFAX 2100 multiplate reader (Awareness Technology, USA) at a wavelength of $570 \mathrm{~nm}$.

Results: The 7-day phototherapy course leads to an increase of proliferation of FB (as compared with the initial level) and $\mathrm{KC}$ (as compared with the postsurgery level) by 22 and $28 \%$, respectively. The proliferative activity of BT474, Hs578T, and A431 tumor cells decreased as compared with the presurgery (initial) level by $31.5,8.97$, and $6.47 \%$, respectively, and as compared with the postsurgery levelby $32,16,8.65$, and $6.26 \%$ for the BT- 474 , HBL-100, Hs578T, and A431 cells, respectively.

Conclusion: The obtained results argue in favor of oncologic safety of the course of phototherapy with VIS and nIR light of $\mathrm{BC}$ patients at the period of the postsurgery rehabilitation. The possible reason of this is that phototherapy can change the balance of proliferation and cell loss in tumors.

\section{PREVENTION OF POSTRADIATION DAMAGES IN PATIENTS WITH PROSTATIC CANCER WITH LOW POWER PHOTOTHERAPY AND THEIR SURVIVAL ANALYSIS FROM THE POINT OF VIEW OF «BALANCE-THERAPY»}

$\underline{\text { A.A. Zimin }}^{1}$, G.M. Zharinov ${ }^{1}$, K.A. Samoilova ${ }^{2}$, N.Yu. $\overline{\text { Neklasova }}^{1}$, L.A. Volodina ${ }^{1}$

${ }^{1}$ Russian Research Center of Radiology and Surgical Technologies, St. Petersburg, Russia

${ }^{2}$ Institute of Cytology, Russian Academy of Sciences, St. Petersburg, Russia

Background: Low power visible and near IR (nIR) light has already been used in oncology for many years for treatment of complications appearing after radiotherapy and surgical treatment of tumors of various localizations, however, data on effect of such accompanying therapy on frequency of radiation lesions in deeply located organs (urinary bladder, rectum) in patients with prostate cancer (PC) are absent. Moreover, there is only a handful of information on survival of patients with cancer after radiotherapy and phototherapy.

Purpose: To study the effect of phototherapy with nIR laser on incidence of late radiation lesions of urinary bladder and rectum in patients with prostate cancer after distant radiation therapy (DRT) and analysis of 5-year survival rates of these patients.

Material and methods: 820 patients with PC of I-IV stages were submitted to DRT and hormonal therapy from January
2000 to June 2009. Patients were divided into the control ( $n=$ $455)$ and the main $(n=365)$ group. In control group, prevention of radiation damages was realized by the commonly accepted scheme. Patients of the main group were additionally given the 12-day course of phototherapy with the matrix photodiode apparatus "Lasernoe Solnyshko" (NIIEFA, St. Petersburg, $\lambda=890 \mathrm{~nm}, 45 \mathrm{~mW}$, $10.8 \mathrm{~J}$, pulsed-periodic mode, duration of pulses from 120 to $150 \mathrm{~ns}$, frequency of pulses from 80 to $3000 \mathrm{~Hz}$ ). Action of light was performed onto the skin areas submitted to DRT beginning with its 12th session. To evaluate statistical significance of differences in frequency of radiation complications, the $\chi 2$ criterion was used. Kaplan-Meier method was used for survival analysis.

Results: In the control group, frequency of radiation reactions from urinary bladder amounted to $2.6 \%$, whereas in patients of the main group - to $0.27 \%(p<0.05)$. Frequency of radiation reactions from rectum in control group was $3.73 \%$, while in the main group $-1.4 \%(p<$ $0.05)$. Differences were also recorded in the degree of expression of complications produced by radiation therapy. In the control group, complications from urinary bladder of I, II, and IV degrees were noticed in patients with localized, locally-spread, and generalized PC forms, whereas in patients obtaining phototherapy, complications of II degree were recorded only in patients with the generalized PC form. In control group, radiation damages of rectum of I, II, and III degrees were present in patients of all PC forms, while in the main group, complications of I-III degrees were revealed only in patients with localized and generalized PC forms. Added to this, in patients with locally-spread PC the survival analysis revealed statistically significant difference between the control $(67 \pm 0.08 \%)$ and main groups ( $89 \pm$ $0.04 \%$ ). The possible explanation of obtained data is discussed from the point of view of balance-therapy that takes into consideration cell loss factor.

Conclusion: In patients with PC after course of phototherapy with the low power nIR radiation of photodiodes, frequency of radiation lesions of urinary bladder and rectum decreased; also decreased was expression of the degree of these lesions. Moreover, nIR phototherapy did not deteriorated the survival rates in patients with PC that can be explained by the positive impact of phototherapy on cell loss factor.

EVALUATION OF LASER PHOTOBIOMODULATION ON HEALING OF BONE DEFECTS GRAFTED WITH BOVINE BONE IN DIABETIC RATS GM Paraguassúa, MDMC Lino ${ }^{\mathrm{a}}$, FB Carvalho ${ }^{\mathrm{a}}$, MC Cangussu $^{\mathrm{b}}$, ALB Pinheiro ${ }^{\mathrm{a}, \mathrm{d}, \mathrm{e}}$, LMP Ramalho ${ }^{\mathrm{a}, \mathrm{c}}$

${ }^{a}$ Center of Biophotonics, School of Dentistry, Federal University of Bahia, Salvador, Bahia, Brazil 
${ }^{\mathrm{b}}$ Oral Epidemiology and Public Health, School of Dentistry, Federal University of Bahia, Salvador, BA, Brazil

${ }^{c}$ Laboratory of Surgical Pathology, School of Dentistry, Federal University of Bahia, Salvador, Bahia, Brazil

${ }^{\mathrm{d}}$ Univ. of Camilo Castelo Branco, São José dos Campos, São Paulo, Brazil

${ }^{\mathrm{e}}$ National Inst. of Optics and Photonics, Phys. Inst, S. Carlos, São Paulo, Brazil

Previous studies have shown positive effects of Low Level Laser Therapy (LLLT) on the repair of bone defects, but there are only a few that associates bone healing in the presence of a metabolic disorder as Diabetes Melitus. The aim of this study was to assess histologically the effect of LLLT (AsGaAl,780 nm,70 mW,CW,ø 0.4 mm), associated with bovine bone graft, on the repair of surgical defects created in the femur of diabetic and non-diabetic rats. Surgical bone defects were created in 60 animals divided into four groups: Group B (non-diabetic + biomaterial); Group BL (non-diabetic + biomaterial + LLLT); Group BD (diabetic + biomaterial); Group BDL (diabetic + biomaterial + LLLT). The irradiated group received $16 \mathrm{~J} / \mathrm{cm}^{2}$ per session divided into four points around the defect, being the first irradiation immediately after surgery and repeated every $48 \mathrm{~h}$ for 14 days. The animals were killed 15, 21 and 30 days after surgery. The results showed inflammation more intense in the BD and BDL groups than in the $\mathrm{B}$ and $\mathrm{BL}$ groups in the period of 15 days $(p=0.023)$, however the cortical repair in the BDL group showed above $25 \%$ in more half of the specimens, while in the BD group the repair was up to $25 \%$ in all specimens. In 30 days, the osteoblastic activity and collagen deposition were significantly higher in the B group when compared to the $\mathrm{BD}$ group. Bone formation was higher in the $\mathrm{BL}$ group $(p=0.023)$ than in $\mathrm{BDL}$ group. It is concluded that LLLT has a positive biomodulative effect in the early stages of the healing process of bone defects in diabetic animals.

\section{PROFILING OF GENES CENTRAL TO WOUND HEALING FOLLOWING LOW INTENSITY LASER IRRADIATION}

\section{N. Houreld, H Abrahamse}

Laser Research Centre, University of Johannesburg nhoureld@uj.ac.za

Background: Wound healing involves three overlapping phases: inflammation, granulation and tissue remodelling. This process is controlled by a variety of cells, cytokines and growth factors. If this process is disrupted, delayed wound healing ensues, a common complication seen in diabetic patients. Low intensity laser irradiation (LILI) has been found to promote healing in such patients. However, the exact mechanisms of action are poorly understood. Purpose: This study aims to profile the expression of key genes central to the wound healing response.

Materials and Methods: Diabetic wounded fibroblast cells were exposed to a wavelength of $636 \mathrm{~nm}$ and a fluence of $5 \mathrm{~J} / \mathrm{cm} 2$ and incubated for $30 \mathrm{~min}$. Total RNA was isolated and $1 \mu \mathrm{g}$ reverse transcribed into cDNA. This cDNA template was used for real-time polymerase chain reaction (PCR) array analysis. The array contained genes important for each of the three phases of wound healing, including extracellular matrix (ECM) remodelling factors, inflammatory cytokines and chemokines, as well as growth factors and major signalling molecules. PCR array data was normalised against five housekeeping genes.

Results: Collagen type I, III, IV and V, matrix metallopeptidase-2, -7 and -9 were up-regulated, while TIMP metallopeptidase inhibitor 1 was down-regulated. Inflammatory cytokines and chemokines were downregulated. A variety of growth factors, including transforming growth factor beta 1 and platelet derived growth factor, and signal transduction molecules such as catenin and mitogen-activated protein kinase 1 were up-regulated.

Discussion and Conclusion: This study helps understand the mechanisms of LILI in diabetic wound healing, and gives information on activation of genes in response to LILI.

\section{IS THERE REALLY A THRESHOLD OBSERVED IN LLLT? IS THERE A THRESHOLD BASED ON PHYSICAL PROPERTIES?}

\section{Hans A. Romberg, MD}

Dr. Hans Romberg Medizintechnik, Schillerstr. 44, D 76297 Stutensee, Germany; and 3 M, Unter der Schanz 2, D 69117 Heidelberg, Germany

A threshold, defined as a minimal dose below that there is no effect, is often claimed to have been observed in LLLT. Whilst a practical threshold might be justified, a linear dose-effect relation (without a threshold) plotted on a logarithmical dosage scale might feign a threshold This effect should be taken into account upon interpreting clinical, and in vitro, data.

Out of basic quantum physical considerations there is a lower limit for a threshold: the dosage where only one photon is absorbed per aimed-at structure in an aimed-at time interval. Taking into account mean values of absorption and scattering, rough estimates can be yielded on upper limits for working depth as a function of wavelength. It is clearly seen that increasing the laser power does NOT yield accordingly higher working depth. 
DIFFERENTIAL RESPONSE OF CENTRAL AND PERIPHERAL NEURONS TO LIGHT IN AN IN VITRO DIABETIC MODEL

J. Anders, Xingjia Wu, Stephanie Alberico, Helina Moges, Jason Smith ${ }^{2}$ and Brian Pryor ${ }^{2}$

${ }^{1}$ Uniformed Services University Bethesda, USA

${ }^{2}$ Lite Cure LLC

Neuropathy is a serious complication of diabetes. Hyperglycemic damage to sensory neurons results in pain and loss or alteration of sensation. This study examined the potential of light for treatment of neuropathy using an in vitro diabetic model. Rat cortical and dorsal root ganglion (DRGs) neurons were cultured in media with either normal $(25 \mathrm{mM})$ or high $(180 \mathrm{mM})$ glucose. Neurons cultured in high glucose were irradiated immediately after seeding and $24 \mathrm{~h}$ later with $980 \mathrm{~nm}$ wavelength light at a power density of $10 \mathrm{~mW} / \mathrm{cm}^{2}$ and fluences of $0.01,0.1,0.5,2,10,50$, 200,1000 and $5000 \mathrm{~mJ} / \mathrm{cm}^{2}$. Cells were fixed at $48 \mathrm{~h}$ postseeding. For each group, 75 to 130 individual neurons were randomly selected and digitally photographed. Neurite extension was measured using NeuronJ. High glucose concentrations in the media of both types of neurons significantly suppressed neurite extension. For cortical neurons in medium with $180 \mathrm{mM}$ glucose, $980 \mathrm{~nm}$ light irradiation significantly promoted neurite extension to lengths comparable to those of the control neurons at fluences of 2, 10, 50 and $200 \mathrm{~mJ} / \mathrm{cm}^{2}$. For the hyperglycemic DRGs neurons, irradiation with $980 \mathrm{~nm}$ light did not improve neurite extension. A primary cellular chromophore for light of red and near infrared wavelengths is cytochrome $\mathrm{C}$ oxidase of mitochondria. It is known that high glucose induced injury in DRG neurons involves mitochondrial damage including loss of cytochrome $\mathrm{C}$. We hypothesize that the differential response of the cortical and DRG neurons to light is due to DRG mitochondrial hyperglycemic mediated injury.

\section{DIABETIC DISTAL SYMMETRIC POLYNEUROPATHY: EFFECT OF LOW INTENSITY LASER THERAPY}

Khamseh M. MD ${ }^{1}$, Kazemikho N. MD. Ph.D candidate ${ }^{*^{2}}$, Aghili R. MD ${ }^{1}$, Forough B. $\mathbf{M D}^{3}$, Lajevardi $\mathbf{M}^{4}$, Dabbaghian F.H. MD ${ }^{5}$, Gooshegir A. MD ${ }^{5}$, Malek M. MD

${ }^{1}$ Institute of Metabolism and Endocrinology, University of Medical Science, Tehran, Iran.

${ }^{2}$ Department of Genetic, Medical Faculty, Tehran University.

${ }^{3}$ Department of physical medicine and rehabilitation, Firoozgar hospital, Tehran University of Medical Sciences, Tehran, Iran

${ }^{4}$ Department of Laser, Milad Hospital, Tehran, Iran
${ }^{5}$ Research Institute for Islamic and Complementary Medicine. Iran University

${ }^{6}$ Mojtaba Malek: Institute of Metabolism and Endocrinology, University of Medical Science,Tehran, Iran

Background: Low intensity laser therapy (LILT) has been considered as a treatment modality in diabetic distal symmetric polyneuropathy (DSP).

Purpose: The aim of this study was to determine the effectiveness of LILT on DSP.

Material and Methods: We examined 107 subjects with type 2 diabetes for detection of DSP using Michigan Neuropathy Screening Instrument (MNSI). Seventeen subjects were eligible to be enrolled in the study. Nerve conduction studies (NCS) were performed in all eligible subjects as an objective method to confirm neuropathy. The participants received LILT three times a week for 10 sessions. NCSs were re-evaluated after completion of the treatment. The absolute changes in NCS parameters were considered to establish the effectiveness of the treatment.

Results: Baseline demograsphics were similar in all participants. The mean differences of NCV parameters were considered for comparison. At the end of the study the subjects showed a significant increase in neural potential amplitudes.

\section{A SIMPLE MODEL FOR THE BIPHASIC DOSE-EFFECT RELATION OBSERVED IN LLLT}

Hans A. Romberg, M.D.

Dr. Hans Romberg Medizintechnik, Schillerstr. 44, D 76297 Stutensee, Germany; and I3M, Unter der Schanz 2, D 69117 Heidelberg, Germany

Several mechanisms of action have been proposed for LLLT. Due to properties of our biochemistry any of these mechanisms should be saturable. A simple model is proposed adding the results of several LLLT action pathways. Each pathway of action may have specific effectivity, and saturation level. If negative effectivity is taken into account, (counterproductive actions), even very simple models can yield dose-effect relations similar to those often observed in LLLT [1]. This model could possibly be used to prove, or to falsify, proposed mechanisms: the saturation level could be measured in vitro and compared to the measured light intensity at optimal dosage in vivo. If no correlation is found, most probably that mechanism is not the dominant one; or the structure in vivo, where the light intensity has been measured, is not the dominant structure of therapeutical effect.

[1] Y-Y. Huang, A. C.-H. Chen, J.D. Caroll, and M.R. Hamblin, "Biphasic Dose Response in Low Level Light Therapy", Dose Response. 2009; 7(4): 358-383 
INDUCTION OF AUTOLOGOUS BONE MARROW STEM CELLS BY LOW ENERGY LASER THERAPY HAS BENEFICIAL EFFECTS ON KIDNEY POST ISCHEMIA-REPERFUSION INJURY IN THE RAT

Hana Tuby, Lidya Maltz, and Uri Oron

Department of Zoology, The George S. Wise Faculty of Life Sciences, Tel-Aviv

University, Tel-Aviv, 69978, Israel

Low level laser therapy (LLLT) has been found to modulate biological activity. The aim of the present study was to investigate the possible beneficial effects of laser application on stem cells in the bone marrow on the kidney of rats that underwent ischemia/reperfusion (IR) injury. A total of 32 Wistar male rats, that underwent IR to the kidney were used. IR injury was induced by occlusion of the renal artery for 15 or $30 \mathrm{~min}$. Rats were divided randomly into two groups of control and laser treated rats. Laser therapy (GaAl-As $810 \mathrm{~nm}, 200 \mathrm{~mW}$ output, for $2 \mathrm{~min}$ ) was applied to the bone marrow 1 and 7 days post IR injury to the kidneys and rats were sacrificed 2 weeks later. Kidneys were processed for histology (light microscopy and immunohistochemistry of mesenchymal stem cells (MSCs) using c-kit as marker). Tissue homogenates were also prepared from the kidneys for biochemical analysis of succinic dehydrogenase activity (SDH), a mitochondrial activity marker. The microscopic examination of the histologial sections demonstrated that the dilatation of the renal tubules was reduced in the laser treated rats as compared to the control non laser irradiated group. C-kit positive cell density in kidneys of the laser-treated group that was IR injured was significantly ( $p=$ 0.015) 3.2-fold higher compared to the control group. The $\mathrm{SDH}$ results indicate that laser application to BM caused a significant $(p=0.02)$ elevation of 1.5 -fold in the enzymatic activity in the kidneys as compared to the control group.

It is concluded that LLLT application to the BM causes a significant increase in the density of MSCs in the kidney post IR injury probably by induction of stem cells in the $\mathrm{BM}$ that are consequently mobilized to the IR injured kidney. These MSCs may secrete growth factors that induce better preservation of the kidney tissue and its mitochondrial activity. The mechanisms associated with the above phenomenon will have to be elucidated by further studies.

\section{NON SURGICAL LASER IN REGENERATIVE MEDICINE: THERAPY OF TRAUMATIC CENTRAL NERVOUS SYSTEM INJURIES}

\section{Longo, MD}

Specialization School in General Surgery, Siena University, Institute Laser Medicine, Firenze - Italy

longo.leonardo@gmail.com
Background and Purpose: Aim of our study is to confirm the validity and positive follow up of Non Surgical Laser Therapy (NSLT) on patients with Traumatic Central Nervous System Injuries (TCNSI).

Material and Methods: Patients enrolled have traumatic spinal cord and brain injuries, occurred at least 1 year before laser treatment and documented by EEG, NMR, ESSP and EMG. All patients have total and/or subtotal sensory and motor paralysis under lesion level, clasified as ASIA A in clinical classification of this type of lesion. Lasers used were $808 \mathrm{~nm}$ and $10600 \mathrm{~nm}$ and applied with a first cycle of 20 sessions, four a day. Second and third cycle were repeated with interval of 1 month between the cycles. A therapy protocol was used according to the clinical conditions of each patient. If not significant improvement are noted after first cycle of laser therapy, the treatment is interrupted.

Results and Conclusions: In our experience on 96 patients with TCNSI, after first cycle of laser therapy, 92 had improvement of sensory, motor and voluntary functions confirmed using evaluation tests, ASIA, Franklin and Asworth classification and recorded by EEG, RMN, ESSP and EMG. Further improvement was noted after each cycle. No unpleasant side effects were noted, as expected by the laws of photobiology. Furthermore laser treatment did not cause any worsening of the spinal function. The results achieved did not disappeared after the end of the treatment, as confirmed by the follow-up (in some patients more than 5 years). The remaining four patients did not show any change, for reasons under investigation.

\section{PERIODONTITIS DIAGNOSTICS ON THE BASIS OF SALIVA RAMAN SPECTROSCOPY}

\section{S.A. Gonchukov and A.V. Sukhinina}

Moscow State Engineering Physics Institute, Moscow, Russia gonchukov@mephi.ru

Background: It is considered, that each adult suffers from periodontitis in a greater or lesser degree. Its development can lead to serious oral illness and to the loss of teeth. With the object of periodontitis detection the doctors traditionally examine oral cavity using tactile, visual, or radiograph methods. The investigations showed that the ultrasonic, IR, $\mathrm{THz}$, OCT imaging, light scattering, and fluorescent spectroscopy can be also used. As a rule, the approach is based on detecting the dental plaque and calculus. However their existence does not correspond to early stage of periodontitis and can not be used as predictive parameter for oral disease.

Purpose: Raman spectroscopy allows the substances at a molecular level to be analyzed, giving the information about the structure and properties of biological tissues. 
Among the different biological subjects under consideration the saliva is very informative and interesting for both investigators and clinicians. Saliva contains a lot of biomarkers and bacteria that may signalize the different diseases beginning and pathological factors. To our knowledge, there have not been published any experiments that involve saliva for periodontitis diagnostic with the help of Raman spectroscopy. The aim of this study is identifying and determination of biomarkers of periodontitis development using Raman spectroscopy of saliva at a molecular level.

Material and Methods: Oral fluid was obtained from patients with different severity periodontitis and from healthy volunteers. The investigations were performed with dry saliva using a confocal Raman spectrometer Nicolet Almega XR, equipped with 20x long-range microscope. $\mathrm{Nd}$ :YAG laser $(532 \mathrm{~nm}, 15 \mathrm{~mW})$ was used as excitation radiation source. The Raman vibrations in the 500$200 \mathrm{~cm}^{-1}$ spectral region were analyzed. The spectral resolution was $4 \mathrm{~cm}^{-1}$. The exposure time for every spot was $3 \mathrm{~s}$ with 15 scans accumulation. $30 \mathrm{~s}$ photobleaching was used for fluorescence suppression before spectra collection.

Results: Photos of dried saliva samples in norm and pathology were taken with the help of microscope for micro crystallization structure visualization. Normal saliva has a picture of big long crystal structures conjoined with each other and having a tree-like or fern-like form located mainly in the centre of the drop. Under pathology dendrite crystals have smaller sizes and irregular form, also located in a grid-form in the drop. It was revealed that the best spectral lines resolution with good intensity was obtained at the top of volume depositions. Apparently mucins of saliva pull a lot of organic and nonorganic contents exactly in these depositions. Spectral content of spectra from the top of volume structures and plane spots is the same as analyzed, so then spectra were collected only from volume structures. Spectral components of saliva have contributions from multiple chemical species. The whole saliva contains water on $94-99 \%$ and dry residual. Inorganic matter is presented by $\mathrm{Na}^{+}, \mathrm{K}^{+}, \mathrm{Ca}^{2+}, \mathrm{Mo}^{6+}$ in a greater degree, mineral substances are in ion forms and in molecules. Organic matter is presented by different kinds of proteins, polypeptides, immunoglobulins, lipids, vitamins, hormones, organic acids. However it is clearly seen that spectra of normal saliva differ from pathological saliva. We have marked four spectral ranges: $1611 \mathrm{~cm}^{-1}, 1525 \mathrm{~cm}^{-1}$, $1155 \mathrm{~cm}^{-1}$, and $1033 \mathrm{~cm}^{-1}$. Line intensities within these ranges correlate univocal with the level periodontitis.

Conclusion: The comparison of Raman spectra between normal and pathological saliva allowed us to be the first to determine effective biomarkers for identification of periodontitis at early, moderate, severe, and chronic stages.
This work was supported by the Russian Foundation for Basic Research, Grant No 09-02-00515.

\section{LASER MONITORING OF RESPIRATION ACTIVITY IN PRETERM INFANTS: MONITORING OF PECULIAR EVENTS.}

L. Scalise, Eng. Paolo Marchionni, Ilaria Ercoli, Enrico Primo Tomasini

Dipartimento di Ingegneria Industriale e Scienze Matematiche, Università Politecnica delle Marche - Ancona University, Italy

Background: Neonatal Intensive Care Unit (NICU) are highly specialized units of pediatric hospitals taking care of preterm patients as well as ill infants most of the time underweight and possibly in critical conditions. Many physiological signals from NICU patient are continuously monitored (heart rate, respiration rate, blood saturation, etc.) in order to offer a timely cares. Most of the time the instrumentation used is invasive and in contact with the patient.

Aim: In this paper, we propose a novel measurement system for the non-contact assessment of the respiration activity in preterm patients. In particular, we report the results measured on patients undergoing peculiar respiration events such as: irregular respiration behaviors, hiccups and apneas.

Material and Methods: The system is based on the use of a laser Doppler vibrometer (LDVi) [1-3], measuring the displacement of the patient chest from a distance of few meters and by means of a low-power laser beam. The LDVi has been connected to a PC and data are recorded and directly reported on a monitor, allowing a direct monitoring (live) of the respiration conditions of the patient. LDVi data have been processed using Wavelet Analysis in order to enhance the signal-to-noise ratio. The experimental set-up is completed mechanical ventilator providing the reference data on the respiration rate. The subjects population was composed by Five patients ( 3 males 3 females). All patients were recovered in the Neonatal Intensive Care Unit (NICU) department of the "G. Salesi" hospital.

Results: Normal respiration patterns are compared with abnormal ones. In particular, sudden apneas events have been individuated (and confirmed by reference instrumentation) during night surveillance. Hiccups as well as irregular respiration events were also individuated after eating.

Discussion and Conclusion: LDVi respiration monitoring is a valid respiration behavior monitoring technique. It's ability in detecting normal as well as abnormal respiration pattern has been demonstrated in-vivo on neonatal intensive care units. 
References: 1. L. Scalise, U. Morbiducci "Non contact cardiac monitoring from carotid artery using optical vibrocardiography", Medical Engineering \& Physics, 30, 4, pp. 490-497, 2007.2. L. Scalise et al. "From cardiac to respiratory rate, from cardiac sounds to pulse velocity : a non contact, unified approach for the monitoring of vita! 1 signs by means of optical vibrocardiography", Proc SPIE, 8th Int Conf on Vibration Measurements by Laser Techniques, Ancona, 2008.3. L.Scalise, P. Marchionni, I.Ercoli, E. P. Tomasini. "Non-contact laser-based human respiration rate measurement". Proceedings of Laser Florence Conference, AIP, 2010.

THE MULTISPECTRAL VISUALIZATION OF GLIAL BRAIN TUMORS CONTAINING PPIX IN DIFFUSE AND LASER-INDUCED FLUORESCENT LIGHT

Tatiana Savelieva Vavilova, M.V. Loschenov, K.G. Linkov

Prokhorov General Physics Institute of the Russian Academy of Sciences (GPI RAS)

savelevat@gmail.com

There are two main problems in neurosurgery of glial brain tumors which are characterized by the infiltrative growth and by ambiguity of tumor border detection. First of all it is a lack of fast and sensitive methods to quantify the main biochemical alterations in a tumor. And the second problem is the restrictions of the violet excited fluorescence visualization typically used in the neurosurgery such as a small depth of light penetration in a tissue and shielding of a tumor by blood.

To quantify the concentration of the main chromophores and the fluorochromes subjected to alterations in brain tumors the multispectral imaging system is proposed.

It consists of the two light sources for tissue surface irradiation with the broadband white light and the laser light near the absorption peak of protoporphyrin IX (PPIX) in the red region $(634 \mathrm{~nm})$. To provide the simultaneous illumination the white light is filtered with maximum transmittance in the interval $500 \mathrm{~nm}-600 \mathrm{~nm}$. The set of the bandpass filters is used to register images in light diffusely reflected from the tissue and in fluorescent light near the $710 \mathrm{~nm}$. The last signal allows estimating the PPIX concentration in a tissue. It provides the correct deconvolution of spectrally resolved two-dimensional data in diffuse light to quantify concentration and oxygen saturation of hemoglobin.

This multispectral system was approbated on the tissue phantoms with the optical properties corresponding to the optical properties of normal and tumorous glial tissues in vivo and laboratory animals.

\section{ASSESSMENT OF FLUORESCENCE SPECTRA OF DRIED SALINE USED TO UTERINE HYDROSONOGRAPHY}

V. Gegzna ${ }^{1,2}$, P. Sladkevicius ${ }^{3}$, A. Vaitkuviene ${ }^{1}$, J. Vaitkus ${ }^{1}$

${ }^{1}$ Institute of Applied Research, Vilnius University, Vilnius, Lithuania

${ }^{2}$ Faculty of Natural Sciences, Vilnius University, Vilnius, Lithuania

${ }^{3}$ Dept of Obstetrics and Gynecology, Skanes University Hospital, Malmo, Sweden

Background: Methods of fluorescence spectroscopy are not used yet to diagnose endometrium pathologies.

Purpose: To examine fluorescence spectra of saline after being in contact with normal endometrium.

Material and Methods: Saline is injected to uterine cavity during assessment of endometrium by transvaginal ultrasound examination. After examination the saline was collected back to syringe. Fluid drops were dried on silicon plates. Microlaser STA-01-TH (355 nm) was used to excite fluorescence of the drops and fluorescence spectra were registered. The areas under fluorescence curves in various regions of the spectra were extracted using spectra filtration method [1] and then analyzed in groups of proliferative (3 samples), secretory (3 samples) and postmenopausal (4 samples) endometrium using statistical receiver operating characteristic (ROC) method. The groups were determined by anamnesis and the results of ultrasound examinations.

Results: In our experiment the most useful region for fluorescence spectra differentiation was $\sim 470-570 \mathrm{~nm}$. The fluorescence spectra were different between groups of endometria in proliferative and secretory phases as well as in proliferative phase and menopause.

Discussion and Conclusion: We described the fluorescence spectra of saline which had contact with endometria of various states. The causes of differences found are unclear. However, these curves may lay basis for studies of pathological endometria.

\section{References:}

1. Gegzna V, Varanius D, Vaitkuviene A, Kurtinaitiene R, Vaitkus J. Method of cervical smears material autoflorescence spectra filtration for cervical pre-cancer diagnostics. Open Readings 2011: 54th Scientific Conference for Young Students of Physics and Natural Sciences (2011). Vilnius, pp. 117-118.

PHENOTHIAZINES MOLECULAR MODIFICATIONS AT INTERACTION WITH LASER BEAMS

M.L. Pascu $^{1}$ * A.Smarandache ${ }^{1}$, J.Kristiansen ${ }^{2}$, A.Militaru $^{1}$, V. Nastasa ${ }^{1}$, L. Amaral ${ }^{3}$

${ }^{1}$ National Institute for Laser, Plasma and Radiation Physics, Magurele, Romania 
${ }^{2}$ Unit of Mycobacteriology and UPMM, Instituto de Higiene e Medicina Tropical, Universidade Nova de Lisboa, Lisbon, Portugal

${ }^{3}$ Department of Clinical Microbiology, Sønderborg Sygehus, Denmark

In the past decade there are many studies concerning the occurrence, evolution, detection and removal of some pharmaceutical pollutants related to the environment. They are focused on the most frequent used drugs: antibiotics, analgesics, $\beta$-blockers, some neuro-psychiatrics. Considering the last category this report is focused on the Phenothiazines class, particularly on Thioridazine (TZ) (10-[2-(1-methyl-2-piperidyl) ethyl]-2-(methylthio)phenothiazine) that is a piperidine antipsychotic drug belonging to the phenothiazines group. Recent studies have shown the phenothiazines antibacterial properties, which allow to consider them in the context of reversal of drug resistance. $\mathrm{TZ}$ is a compound which exists in two mirror image forms: enantiomers that have the same physical properties except for their interaction with polarized light which leads to the rotation of the plane of polarization. This property is used for chiral compounds and the direction of the rotation is given by $(+)$ for right-rotation and $(-)$ for left-rotation. The sum of the polarization degree of the enantiomers may be zero for racemic mixture -Rac.This study, reports the time evolution absorption measurements of Thioridazine $\mathrm{HCl}$ (Thr) in its three forms: $\mathrm{Rac} /(-)$ and/(+). The stability measurements were carried out on solutions in ultra-pure, de-ionized water. The concentration range was $10^{-5} \mathrm{M}-$ $10^{-3} \mathrm{M}$. The samples were kept at a set of three temperature/light conditions: $4^{\circ} \mathrm{C}$ in dark, $22^{\circ} \mathrm{C}$ in dark and $22^{\circ} \mathrm{C}$ in daylight. The absorption spectra were recorded between (200-1300)nm, with an error limit of $\pm 0.004 \%$. Optical cells of $1 \mathrm{~cm}$ thickness were used. The absorption spectra exhibit broad peaks in UV at 262 and $313 \mathrm{~nm}$ and very large peaks in NIR at 966, 1153 and $1240 \mathrm{~nm}$. In daylight conditions, the $10^{-3} \mathrm{M}$ solutions change their color as follows: after $\sim 45 \mathrm{~h}$ in light-blue, after $\sim 70 \mathrm{~h}$ in bluegreen, after $\sim 96 \mathrm{~h}$ in light-yellow and after $\sim 150 \mathrm{~h}$ in lightbrown. These changes are associated with the appearance in the absorption spectra of two peaks at 632 and $882 \mathrm{~nm}$.We exposed $\mathrm{Rac} /(-) /(+) 10^{-5} \mathrm{M}$ solutions at $266 \mathrm{~nm} \mathrm{Nd:YAG}$ pulsed laser radiation for $1 \mathrm{~h}, 2 \mathrm{~h}$ and $3 \mathrm{~h}$. The laser beam reprate is 10pps, the pulse FTW 5 ns and the average energy on the sample $0.263 \mathrm{~mJ}$. Following the irradiation, the absorption spectra were recorded using $1 \mathrm{~cm}$ optical length cell. The spectra show a flattening of the curves when the exposure time is increased; Rac/(-)/(+) $5 \times 10^{-2} \mathrm{M}$ solutions were exposed at $355 \mathrm{~nm} \mathrm{Nd}$ :YAG pulsed laser radiation for $1,5,10,15$ and $30 \mathrm{~min}$, as well. The laser beam had the same characteristics except for the beam energy $(30 \mathrm{~mJ} /$ pulse). The absorption spectra following irradiation were made in $1 \mathrm{~mm}$ optical length cells. These spectra marked the appearance of the $632 \mathrm{~nm}$ peak, but only for $1 \mathrm{~min}$ and $5 \mathrm{~min}$ irradiation time.

In conclusion, the exposure of $\mathrm{TZ}$ solutions in water to optical coherent/uncoherent light, leads at short irradiation times to reversible modifications of the $\mathrm{TZ}$ molecules structure.

\section{LASER SOLIDIFICATION OF INJECTABLE SCAFFOLDS}

Evgeny Antonov, V.N. Bagratashvili, I.A. Borschenko, B.N. Khlebtsov, N.G. Khlebtsov, S.A. Minaeva, V.K. Popov, A.V. Popova

Institute of Laser and Information Technologies, Russian Academy of Sciences, Troitsk

Development of minimally invasive medical approaches is one of the modern trends in spinal surgery. This study is aimed at further developing of our surface selective laser sintering (SSLS) technique of polymer scaffolds for tissue engineering [1], and elaborating the endoscopic laser sintering technique of scaffold fabrication for engineering of spinal discs tissues.

Material and Methods: Polymers were inserted into the cavity (as a model of internal part of spinal disc) through a surgical needle. Solid structures (scaffolds) were sintered from polylactide (PLA) particles (50-200 $\mu \mathrm{m}$ in thickness) and, also, 200-500 $\mu \mathrm{m}$ in diameter polylactoglicolide (PLGA) sutures. PLA particles were transported through the needle in the gel-like form. Sodium alginate was used as gelling agent. Diode laser light $(0.97 \mu \mathrm{m}$ in wavelength) was introduced into the cavity by optical fibre trough the same needle. PLA particles and PLGA sutures were coated by carbon or gold nanoparticles to sensitize the sintering process. Scaffolds were sintered by three different approaches:

- optical fiber was scanned within the injected PLA powder; laser power was ranged from 1 to $10 \mathrm{~W}$; the scanning speed was up to $3 \mathrm{~mm} / \mathrm{s}$.

- the tip of the fiber located coaxially to the end of needle; PLA particles were sintered simultaneously with the gel extrusion from a needle into the cavity.

- sutures of PLGA were inserted into the cavity; optical fiber was scanned inside the cavity, to integrate the neighboring by sintering.

\section{Results:}

- Coreless or solid cylinders were formed by the first approach. The diameter of cylinders was varied from 0.5 to $4 \mathrm{~mm}$ depending on the scanning speed and laser power.

- In the framework of second approach, the solid structures were formed just at the exit of gel into the 
cavity. Size and shape of as formed solid structures were also dependent on laser power and on the gel flow speed.

- When scaffolds were sintered from PLGA sutures, sintered the elastic globular structures were formed.

Discussion and Conclusion: The minimally invasive laser assisted techniques for fabrication of solid bioresorbable structures from polymer particles and sutures inside cavity was developed. These new techniques are promising for engineering of intervertebral discs tissues.

This work was supported by Russian Foundation for Basic Research (grants 10-08-01133, 11-02-00800, 11-02-12114).

1. J.M.Kanczler, et al., Biocompatibility and osteogenic potential of human fetal femur-derived cells on surface selective laser sintered scaffolds, 09, Acta Biomat 5, 2063

\section{EXPANSIVE PROMOTION OF SCIENTIFIC RESEARCH}

\section{Navratil, L. Navratil}

Czech Technical University in Prague, Faculty of Biomedical Engineering, Department of Medical and Humanities. Kladno, Czech Republic

Purpose: This course is an interactive workshop aimed to aid researchers in gaining support for their work through various uses of social media networks, web copywriting, and interacting with the International Press.

Introduction: This workshop will require a hands-on approach from the students, and will cover the arigorous historical scope of researching marketing from the past, present, and future.These skills are absolutely essential in our current world, where grant money is scarce, and numerous ideas that could possibly transform the scientific scope are being tossed by the wayside, due to a lack of proper marketing used in the attempts to attain those limited funds. Another aspect discussed throughout the course, is the actual marketing strategy of the research to the general population. Laser technology is provided as the example for this case. To date, the general public views lasers as a tool of destruction, and the general public remains unaware of their healing properties.

Aim: In today's world, where there is an alarming decrease in the amount of funds granted for scientific activities and studies. Learning how to garner public interest and those thereby acquiring those grants, is absolutely essential.

Many projects that could possibly have major impacts on scientific progress are often played down, due to a lack of outside promotion. Applying tactics and strategies for web and consumer marketing may help secure scientific advancement. Results: The lecture and the tactics discussed therein, will help aid grant accruement in all scientific fields.
Conclusions: Raised awareness of the possible processes leading to further promotion of one's scientific work is the cornerstone on the path to gaining resources from outside funding agencies, allowing for a stronger, more real impact of one's results.

\section{MINIMIZING RISK AND ENSURING QUALITY THROUGH COMPLIANCE WITH INTERNATIONAL SAFETY STANDARDS}

Penny J. Smalley, R.N., CMLSO

Technology Concepts International

Chicago, Illinois, USA

A ever growing number of standards and regulations surrounds the use of medical lasers, and ancillary safety equipment, in healthcare practices around the world.

Medical and nursing professionals are always dedicated to the safe care of patients, however, they are often confused as to how to interpret and implement those rules that govern the use of Class $3 \mathrm{~b}$ and Class 4 healthcare laser systems, and other energy based devices such as IPL systems.

If an accident occurs, it is essential to be able to substantiate clinical practices in evidence based international benchmark standards.

This session will examine current and evolving international standards, including revisions of the IEC, and new draft ISO documents, offering useful practice recommendations, based on a risk management perspective, with a focus on administrative, and procedural control measures.

At the conclusion of this session, participants will:

1. Discuss the scientific basis for laser safety, as a means for risk assessment, and development of control measures.

2. Discuss elements of the international standards, as a basis for operational policies and procedures in healthcare practice settings, in both hospital and office practice environments.

3. Discuss the use of audit as a quality assurance tool for mandating compliance and safe practice.

\section{SURGICAL TREATMENT OF ORAL LESIONS WITH THE CARBON DIOXIDE LASER}

Antonio Pinheiro, Gilberth Tadeu dos Santos Aciole, Jouber Mateus dos Santos Aciole, Luiz Guilherme Pinheiro Soares, Nicole Ribeiro Silva Santos, Jean Nunes dos Santos

Center of Biophotonics, School of Dentistry, Federal University of Bahia

albp@ufba.br

The CO2 laser is the most used surgical laser on the oral cavity due to its affinity to water and high absorption by the 
oral mucosa. Several benefits of the use of the $\mathrm{CO} 2$ laser are reported on the literature on regards of surgical procedures carried out on the oral cavity. The tissue effect of $\mathrm{CO}_{2}$ laser is mainly produced by heat generation. This heat may result in an increase in temperature that carbonizes and vaporizes the irradiated tissues. Laser wounds have a small contraction when compared to conventional wounds made with a scalpel. This phenomenon is due to considerable decrease or absence of myofibroblasts. In addition, hemostasis, reduced scar formation, and immediate sterilization of surgical wounds are other benefits of the $\mathrm{CO}_{2}$ laser. The use of the $\mathrm{CO} 2$ laser does not reduce the risk of relapses of the lesion, but it is an easy technique to use and results on both quick surgical procedure and silent post-operative period.

TM: YAP MICROCHIP LASER FOR DEBONDING CERAMIC ORTHODONTIC BRACKETS - BOND STRENGTHS MEASUREMENT

Tatjana Dostalova, Helena Jelinkova, Jan Sulc, Petr Koranda, Michal Nemec

Charles University, 2nd Medical Faculty, Prague, Czech Republic; CVUT FJFI, Prague, Czech Rep; Sendai National College of Technology, Sendai, Japan

Background: Fixed ceramic orthodontic appliances combine acceptable esthetics for patient and optimal technical performance for dentist. Ceramic brackets can lead to problems such as enamel tear outs or pain at removal because of their low fracture resistance and high bond strengths. Laser systems can be used to eliminate those problems mainly during bracket debonding.

Purpose: The principle of bracket debonding is to degrade the adhesive resin strength connecting the tooth and bracket. The aim of our study was to measure the influence of laser radiation during brackets removal without changes in the enamel structure.

Material and Methods: The laser system was a longitudinally diode-pumped Tm:YAP laser operating at $1997 \mathrm{~nm}$. Ceramic brackets Fascination 2 and Charity SL APC were bonded on 60 teeth. The bracket with the tooth sample was heated by laser light and after the chosen time interval the bracket was removed mechanically from the tooth surface. The digital force gauge FMI Force Gauge FMI-230C5 measured bond strength.

Results: After laser irradiation the bracket can easily be removed without cracks. Tm: YAP microchip laser radiation with power: $1 \mathrm{~W}$; time: $60 \mathrm{~s}$; spot size $3 \mathrm{~mm}$ has direct influence on the adhesive resin strength connecting the tooth and bracket namely by Ceramic bracket Fascination 2 (significant decrease from $63.7 \mathrm{~N}$ (SD 21.5) to $48.8 \mathrm{~N}$ (SD 21.7). Metal component inside bracket Charity SL APC limited laser effect (from 39.6N (SD 11.5) to $35.1 \mathrm{~N}$ (SD 13.5).
Discussion and Conclusion: The diode-pumped Tm:YAP laser operating at $1997 \mathrm{~nm}$ might be an effective clinical way to reduce the shear bond strengths of orthodontic ceramic brackets.

\section{COMPARED ANALYSIS OF THE SHADE, TEMPERATURE AND HP CONCENTRATION DURING DENTAL BLEACHING BY USING TWO DIFFERENT WAVELENGHTS: A PRELIMINARY IN VITRO STUDY WITH KTP AND DIODE LASER Fornaini C, Lagori G, Merigo E, Meleti M, Manfredi E, Vescovi $P$ \\ European Master Degree in Oral Laser Applications, Dental School, Faculty of Medicine, University of Parma (Italy)}

Aim of the study: In the last years many bleaching teeth techniques were proposed, several of them by using laser source in order to enhance the process.. About the exact role of coherent light on the biochemical reaction which leads to the whitening result, opinions are very discordant. The aim of the study is to examine three different factors by comparing two different laser sources.

Material and method: This study was carried out by observing the gel temperature during bleaching process; HP concentration and teeth shade variation before and after bleaching procedure were recorded too. Altogether one hundred sixty bovine teeth were bleached by using a $30 \%$ gel of hydrogen peroxide. Some of them were bleached by using gel only, others by gel plus two different laser wavelengths (532 and $810 \mathrm{~nm}$ )at two different powers (2 and 4 watts).

Results: Data obtained show that KTP laser was the only to produce a significant shade variation with minimal temperature increase. Diode produced the higher temperature elevation with the most important diminish of HP concentration obtaining statistical significant result in term of shade variation only when used at 4 watts. Shade variation produced by diode laser were lower by using KTP laser at 2 watts.

No significant correlation was found between temperature, HP concentration and shade variation.

Conclusion: In this study KTP laser appears to be better than Diode in dental bleaching, obtaining better result with less dangerous thermal increase. This result might call in question most the literature affirming bleaching gel explains its action only with the increase of the temperature by improving the speed of the redox reaction. Further study occour to investigate correlation between parameters variation and efficacy of the bleaching process. 
915 AND 1064 NM COMBINED DIODE LASER IN ORAL SOFT TISSUES SURGERY: IN VITRO AND CLINICAL STUDY

\section{Fornaini C, Rocca JP}

Faculty of Dentistry, University of Nice-Sophia Antipolis (France)

Aim of the study: Since a long time, oral medicine and surgery is looking for lasers that permit to moove wavelenghts according to different target tissues.

The aim of the study is to analyse, by in vitro and clinical tests, the utilisation of a semi-conductor laser delivering both $1064 \mathrm{~nm}, 935 \mathrm{~nm}, 615 \mathrm{~nm}$ plus a blue aiming beam (405 nm). Material and Methods: Firstly several in vitro tests on entracte teeth, by using thermocouples and thermal camera, were performer in order to verify the thermal elevation in target tissues irradiated by the device.

Subsequently the laser was used to cut and coagulate oral soft tissues.

Results: Different delivery systems (fibers, straight and right angle handpieces) allowed to practice in contact mode as well as focal mode and combination of two wavelenghts permitted to solve soft tissue surgical problems: while $915 \mathrm{~nm}$ cuts, $1064 \mathrm{~nm}$ serves for haemostasis.

Discussion: In vitro experiments determined the safe parameters for cuting efficiency avoiding possible thermal damages to the target tissues.

Conclusion: Moreover the use of $1064 \mathrm{~nm}$ alone opens the door for cosmetic dentistry (bleaching), preparationof dentinal surfaces for hypersensitivity treatments and soft laser $(615 \mathrm{~nm})$ is used to enhance healing processes. Further study will be necessary to confirm this preliminary report.

\section{LASERS IN ORAL SOFT TISSUE SURGERY: WHICH WAVELENGTH TO CHOOSE?}

$\underline{\text { Seif Bassel }}{ }^{1}$, Augros $\mathbf{C}^{2}{ }^{2}$, Raybaud $\mathrm{H}^{3}{ }^{3}$, Fornaini $\mathbf{C}^{2}$, $\overline{\text { Rocca } \mathbf{J P}^{2,3}}$

${ }^{1}$ Rue de la Loge, Nice

${ }^{2}$ TELEO Laboratory, University of Nice Sophia Antipolis, France

${ }^{3}$ St Roch University Hospital, Nice, France

Purpose of the study: to prove that the selection of the laser wavelength adapted to different target tissue and medical conditions may solve important clinical problems. Comportment of Er:YAG, Nd:YAG, KTP, Combined 1064 and $930 \mathrm{~nm}$ diode and CO2 lasers are then discussed.

Background: Today a lot of different lasers may be used in current oral soft tissue surgery. The use of lasers in the treatment of such conditions results in significant benefits in comparison to conventional scalpel surgery. Dental practitioners often ask about which wavelength to choose. Two parameters may be evoked: results are operator dependant and the choice of the best adapted laser wavelength helps the practionner and the patient to reach the desired results.

Materials and methods: To guide the practitioner making his decision, different soft tissue procedures such as vestibular deepening, crown lengthening, fibroma excision, leukoplakia, lichen planus, haemangioma and epulis fissuratum were compared once treated with $532 \mathrm{~nm}$, combined 930 and $1064 \mathrm{~nm}, 1064 \mathrm{~nm}$, $2940 \mathrm{~nm}$ and $10600 \mathrm{~nm}$.The efficiency of each laser and the quality of healing process was observed and registered. followed. Pain perception level was measured using a visual analog scale.

Results: In terms of pain threshold, the best results were observed with Er: YAG, differences between KTP, NdYAG, CO2 and Diode being not significant. Vestibular deepening procedure proved to be the least tolerated regardless any wavelength. In terms of quality of healing process, Er:Yag and $\mathrm{CO} 2$ Laser proved to have the fastest and most stable healing process.

Discussion and Conclusion: The use of the adapted wavelength for each procedure helps in obtaining optimized wound healing process with reduced oedema and swelling, reduced postoperative pain, convenient mucosa removal and reduced intensity of inflammatory reaction.

\section{EFFICACY OF ER,CR:YSGG RADIAL FIRING TIPS ON THE LASER ASSISTED ENDODONTIC TREATMENT - BLIND RANDOMIZED CLINICAL TRIAL}

M. Martins, M. Carvalho' ${ }^{1}$, J. Capelas ${ }^{1}$, I. Vaz $^{1}$, M.A. Martins $^{2}$, N. Gutknecht ${ }^{3}$

${ }^{1}$ Faculdade de Medicina Dentária, Oporto University;

${ }^{2}$ UCP-CRB University

${ }^{3}$ RWTH Academy, Aachen University

Laser (Radial Firing Tips) versus the concomitant use of $3 \%$ sodium hypochlorite and interim calcium hydroxide paste in necrotic teeth with apical periodontitis.

Methods: Canals in 36 single-rooted teeth were randomly assigned. In group 1 teeth were prepared and rinsed with $3 \%$ sodium hypochlorite and calcium hydroxide paste was applied interappointment; in group 2 teeth were prepared with saline solution and irradiated with Er,Cr:YSGG laser using the RFT2 $(140 \mu \mathrm{s}, 37.5 \mathrm{~mJ}, 20 \mathrm{~Hz})$ and the RFT3 (140 $\mathrm{ss}, 62.5 \mathrm{~mJ}$, $20 \mathrm{~Hz}$ ) without water and air, in the first and second appointment respectively, four times each, moving at $2 \mathrm{~mm}$. s-1 from apical to coronal. The primary outcome measure was change in apical bone density at 6 months, using the periapical index (PAI) for blind radiographic evaluation. 
Results: Twenty-nine patients were examined and subjected to statistical analysis at the 6 month follow-up, 12 in group 1 and 17 in group 2. There was one treatment failure in group 1. Both groups exhibited a statistically significant decrease in PAI score.

\section{OSTEONECROSIS OF THE JAWS}

AND BISPHOSPHONATES: LASER TREATMENT AND LONG TERM FOLLOW-UP IN 180 PATIENTS Paolo Vescovi ${ }^{1}$, Elisabetta Merigo ${ }^{1 *}$, Maddalena Manfredi $^{1}$, Marco Meleti $^{1}$, Carlo Fornaini ${ }^{1}$, Rebecca Guidotti $^{1}$, Amin Sarraj ${ }^{1}$, Giovanni Mergoni ${ }^{1}$, Jean-Paul Rocca $^{2}$, Samir Nammour ${ }^{3}$

${ }^{1}$ Master Europeo "Laser in Odontostomatologia" European Master Degree in Oral Laser Applications EMDOLA - Università di Parma (Direttore: Prof. Paolo Vescovi)

${ }^{2}$ University of Nice-Sophia Antipolis (France), Faculty of Dentistry, Teleo Lab.

${ }^{3}$ EMDOLA (European Master Degree on Oral Laser Applications) General Coordinator

Background: Osteonecrosis of the jaw (ONJ) is a side effect of bisphosphonate therapy (BPT), described since 2003. The etiology of BRONJ remains unknown and multifactorial pathogenesis seems to be related to various local and general factors.

Several expert groups have developed protocols to facilitate specialists involved in the multidisciplinary management of patients with BRONJ in the prevention of this disease.

Purpose: The purpose of this paper is to provide a concise review of the literature and describe the experience of the University of Parma on 180 patients who underwent BPT for oncological and non oncological disease.

Materials and methods: One hundred sixty-one BRONJ sites were treated with 5 different approaches and, therefore, classified under five different groups:

G1 (32 sites): BRONJ sites treated with medical therapy alone;

G2 (35 sites): BRONJ sites treated with medical therapy and LLLT;

G3 (17 sites): BRONJ sites treated with medical therapy and conventional surgery;

G4 (38 sites): BRONJ sites treated with medical therapy, surgery and traditional LLLT;

G5 (39 sites): BRONJ sites treated with medical therapy, Er:YAG laser-assisted surgery and LLLT.

Results: BRONJ improvement was obtained in a percentage of patients between the $25 \%$ (G1 group) and $97,44 \%$ (G5 group); complete healing of BRONJ lesions was observed in a percentage of patients between the $18,75 \%$ (G1 group) and the $92,31 \%$ (G5 group). The laser-assisted surgical approach obtained as result the complete healing in 3 Stage III BRONJ.

Statistically significant difference was found between the medical therapy group (G1) and the others group.

Discussion and conclusions: In terms of complete healing the introduction of laser-assisted surgical approach in therapeutical protocols improved results particularly in Stage III BRONJ with a bigger percentage of Stage 0 (complete healing) after treatment.

\section{LLLT WITH ND:YAG LASER IN DENTAL EXTRACTIONS IN RATS UNDER ZOLEDRONIC ACID AND DEXAMETHASONE ADMINISTRATION. PILOT STUDY \\ Vescovi $\mathbf{P}^{1}$, Merigo $\mathrm{E}^{1^{*}}$, Corradi $\mathrm{D}^{2}$, Maestri $\mathbf{R}^{2}$, Manfredi $M^{1}$, Meleti $M^{1}$, Fornaini $C^{1}$, Nammour $S^{3}$ \\ ${ }^{1}$ Master Europeo "Laser in Odontostomatologia" - European Master Degree in Oral Laser Applications EMDOLA - (Direttore: Prof. P. Vescovi) - Univ. di Parma - Parma, I \\ ${ }^{2}$ Dipartimento di Patologia e Medicina di Laboratorio - Sezione di Anatomia patologica - Università di Parma, Parma, Italy \\ ${ }^{3}$ EMDOLA (European Master Degree on Oral Laser Applications) General Coordinator}

Background: Bisphosphonates (BPs) inhibit bone turnover and repair capacity after micro-damage and reduce epithelial cell proliferation in vitro and exhibit antiangiogenic properties: due to these properties, they are linked to osteonecrosis of the jaws (ONJ). Low Level Laser Therapy (LLLT) can be effective in bone and mucosal repair and consequently in prevention of BRONJ after Dental Extractions (Des) in patients under BPT.

Purpose: The aim of this study was to analyze the effects of dental extractions and Nd:YAG laser biostimulation in rats under zoledronic acid and steroid therapy with a clinical and histomorphometric analysis.

Material and Methods: Thirty Wistar rats were randomly subdivided into three different groups of 10 rats each: experimental group treated with zoledronic acid (ZOL) (Zometa ${ }^{\circledR}$, Novartis, Basel Switzerland) (Group A); experimental group treated with ZOL plus Dexamethasone (DEX) (Group B); control group without pharmacological treatment (Group C). After 6 weeks of pharmacological treatment, maxillary first molars teeth were bilaterally extracted under general anaesthesia. All groups received LLLT in each left-hand maxillary side immediately after tooth extraction and the following three times in a week under general anaesthesia until the day of sacrifice. LLLT was performed with a Nd:YAG laser $(1064 \mathrm{~nm})$ (Fidelis ${ }^{\circledR}$; Fotona - Slovenia) with the following parameters: $1.25 \mathrm{~W}$ and $15 \mathrm{~Hz}$ in VSP mode, $60 \mathrm{~s}$ for 5 consecutive 
applications. Histopathological analysis was carried out by assessing the degree of surface epithelium healing, the connective tissue and bone regeneration, and the degree of local inflammation.

Results: Three days after the extraction, soft and hard tissues healing was better on the laser side, without a significant statistical difference. Moreover, inflammation degree was significantly lower on the laser sides ( $p=$ 0,0384).

Discussion and conclusion: The significant healing stimulation of LLLT protocol was important in the early stage of repair process both in the control group compared to those treated with zoledronic acid and steroids. LLLT maybe a help during the early stages of recovery after surgical procedures in patients under zoledronic acid

\section{LASER AND SPECIAL CARE DENTISTRY: A NEW PERSPECTIVE}

A. Oppici $^{1}$, F. Clini ${ }^{1}$, C. Fornaini ${ }^{1}$, M. Fontana ${ }^{1}$, L. Cella, E. Merigo 1

${ }^{1}$ U.O.S. Odontostomatology and Maxillo-facial Surgery Unit "Special cares and Special Projects" - Guglielmo da Saliceto"Hospital - Piacenza - Italia

\begin{abstract}
Aim: Special care dentistry is today interested to new operating protocols facilitating the gain of therapeutic goals in a vulnerable population, often with difficult approach and high risk of complications during and after the treatments.

In this process, focused on a continuous clinical and therapeutic treatments quality improvement, hospitals should utilise all the opportunities offered by technology in order to increase the capacity to treat different oro-maxillo-facial diseases, often associated with systemic disorders further complicating the therapeutic process.

The aim of this work is to focalize the attention to the usefulness of laser technology in special care dentistry and to increase the applications of different wavelengths to treat "special needs" patients.
\end{abstract}

Materials and methods: The most part of patients of the Operative Unit of Odontostomatology and Maxillo-facial Surgery "Special cares and Special Projects" of the Hospital of Piacenza is made by carriers of congenital and acquired disorders (cognitive, physical, psychiatric and medical) requiring "special cares" in special locations and with operators able to treat specific tools. The availability of different laser wavelengths (CO2, Diode, Er: YAG demonstrating great efficacy in surgical, conservative and prosthetic dentistry, allows to treat a large part of pathological oral disease in vulnerable population (motility and behavior disease, immune and bleeding disorders, side effects of head and neck chemio-radiotherapy).

Results: Laser-assisted minimally invasive techniques significantly improved therapeutical results, particularly gaining a greater cooperation of patients with behavioral problems, significantly reducing complications in patients at risk of infection and bleeding, improving the quality of life in patients treated for head and neck cancer.

Conclusions: Because of its versatility in all fields of applications, laser-assisted dentistry is a valid option complementary to conventional dental techniques. Hospitals and clinics able to introduce this technique and train operators could offer a better therapeutical option also to special care patients.

\section{LASER IN DENTISTRY. BIOSTIMULATION} AND SURGERY

F. Barzè ${ }^{1}$, B. Palmieri $^{2}$, L. Scalise ${ }^{3}$, V. Rottigni ${ }^{2}$

${ }^{1}$ Professional man, Italy

${ }^{2}$ Department of General Surgery and Surgical Specialties, University of Modena and Reggio Emilia Medical School, Surgical Clinic, Modena, Italy

${ }^{3}$ Dipartimento di Ingegneria Industriale e Scienze Matematiche, Università Politecnica delle Marche - Ancona University, Italy

Introduction: the Authors describe a new infrared dental laser suitable either for biostimulation or surgery. The instrument is compact, easy to be handed and has a very short learning curve. One of the most relevant claims of the instrument is to be operating connected with the patient systolic wave recorded by a fingersticked pulse. In this way, it is possible to synchronize the pulse infrared laser wave output with the peak of blood systole into the target tissue, increasing optimal energy delivery with maximal thermic relaxation and lower thermic damage.

Materials and methods: 40 patients have been treated with this instrument for the treatment of the following pathologies: glossitis, post extraction oedema, traumatic nerve paraesthesias, salivary glands atrophy, labial herpes virus, aphthous stomatitis, frenulectomy, post extraction haemorrhage, epulis, leukoplakia.

Results: the instrument gives excellent results in term of minimal heating and carbonization in the surgical fields and shorter biostimulation time delivery in the non surgical indications compared with not biofeedback related instruments.

Conclusions: the new pulse synchronized infrared dental laser is to be considered a truly innovative approach addressing in medical and surgical dentistry area. 
PRELIMINARY STUDY ON RADIO-CHEMIOINDUCED ORAL MUCOSITIS AND LOW LEVEL LASER THERAPY

Matteo Fontana $^{1^{*}}$, Elisabetta Merigo ${ }^{1-2}$, Carlo Fornaini ${ }^{2}$, Fabio Clini $^{1}$, Luigi Cella ${ }^{1}$, Paolo Vescovi ${ }^{2}$, Aldo Oppici ${ }^{1}$

${ }^{1}$ U.O.S.D. di Odontostomatologia e Chirurgia MaxilloFacciale - Ospedale "Guglielmo da Saliceto" - Piacenza Italia

${ }^{2}$ Master Europeo "Laser in Odontostomatologia" - European Master Degree in Oral Laser Applications EMDOLA Università di Parma (Direttore: Prof. Paolo Vescovi) Università di Parma - Parma - Italia

Background: Oral mucositis remains one of the most common and troubling side effects of antineoplastic radiation and drug therapy: its incidence in oncohematological radio-chemiotreated patients is variable between 50 and $100 \%$ and its impact on this populations is directly linked with the experience of intense pain causing reduction and modification of therapy regimens, decreased survival rates and increased cost of care.

Purpose: Aim of this study is the preliminary evaluation of a Low Level Laser therapy (LLLT) protocol on healing process of oral mucositis and on pain and quality of life of patients experiencing this dramatic side-effect.

Materials and methods: Patients were evaluated and treated at the Unità Operativa Semplice di Odontostomatologia e Chirurgia Maxillo-Facciale of the Hospital of Piacenza were they were treated for primary disease with protocols of chemotherapy and/or radiotherapy. LLLT protocol was performed with a diode laser $(880 \mathrm{~nm}-\mathrm{XD}$ Smile - Fotona -Slovenia) on a 2 weeks- 6 treatments schedule with power of $0.5 \mathrm{~W}$ and application of $30 \mathrm{~s}$. Mucositis grading was scored on the basis of WHO classification by two blind operators at each treatment and at 1 and 2 weeks after treatment. Pain and capability of deglutition were described by patients by means questionnaires based on Visual Analogue Scale, Numerical Rating Scale and Quality of Life.

Results: A relevant improvement of healing of oral mucositis, in terms of reduction of grading score, and of pain, deglutitory discomfort and quality of life was recorded.

Discussion and conclusion: Results of this preliminary study are encouraging for the realization of larger studies focused on the application of LLLT protocols in management of radio-chemiotreated patients with oral mucositis.

\author{
Nd:YAG LASER BLOODLESS TONSILLECTOMY \\ BY FIBEROPTIC DOPPLER COUPLED \\ HANDPIECE BEAM DELIVERY \\ $\underline{\text { B. Palmieri }}^{1}$, V. Rottigni ${ }^{1}$
}

${ }^{1}$ Department of General Surgery and Surgical Specialties, University of Modena and Reggio Emilia Medical School, Surgical Clinic, Modena, Italy

Introduction: the Authors describe a new safe, easy and cheap surgical tonsillectomy approach with very low invasivity. The handpiece encloses a $100 \mu \mathrm{m}$ fiber optic coupled with a very tiny $300 \mu \mathrm{m}$ doppler probe. Accordingly with the protocol, the surgeon explores the tonsils vascular network with the doppler probe, suitable on the top of the handpiece, automatically withdrawning it by simple button pressing on the handle, and immediately advancing with the laser radiating fiber optic into the tonsils parenchyma, quite far from the vascular network, thus avoiding any risk of haemorrage or blood loss. The procedure is repeated several times back and forth through the parenchyma to induce several channels and vaporize the infected tissue into the tonsil. This intracapsular procedure leaves the vascular network and part of the stroma intact.

Materials and methods: A total of 20 patients,affected by chronic hypertrophic tonsillitis with recurrent fever and the classic symptoms related to persisting oral inflammation were recruited. Each patient was injected with $28 \mathrm{G}$ needle $0,5 \mathrm{ml} 1 \%$ xylocaine at each side. A $0,4 \mathrm{~mm}$ size fiber was used connected with 1064 neodymium-yag emitting $200 \mathrm{~J} /$ $\mathrm{mm}^{2}$ energy souls. The procedure requires no more of 5 10 min besides.

Results: the treatment was well tolerated. Complications were observed as follows: after the operation sore throat was reported by 2 patients, oedema by 2 , inflammation of the pharynx by 1 patient, moderate exudate by 1 , local burning by 3 and general discomforts as cough, pruritus, dysphagia, and dryness.

Conclusions: surgical tonsillectomy using 1064 Neodymium-yag is to be considered an innovative approach for safety reasons, acceptable costs-benefits ratio and short and long term recovery.

\section{LASER UVULOPALATOPHARYNGEOPLASTY VERSUS LASER PARTIAL MUCOSAL PALATAL EXCISION AS SURGERICAL TREATMENT OF SIMPLE AND OBSTRUCTIVE SNORING} Khaled Mohamed Bofares, MD

Ass. Prof. Otorhinolaryngology Dept, Omar Almoukhtar University, Elbyda, Libya

Background and objectives: $\mathrm{CO} 2$ laser is now being used for different oropharyngeal surgical procedures. On the other hand one of these surgical interventions are those which performed for the management of patients with palatal flutter who are presented with simple snoring, 
obstructive snoring, and sleep apnea syndrome .There are different verities of these surgical procedures which are tried for this purpose. The most common patterns of these surgeries are uvulopalatopharyngeoplasty (UPPP) and partial mucosal palatal excision (PMPE) which can be done by laser and non-laser techniques. Laser uvulopalatopharyngeoplasty (LUPPP) is suggested to be more beneficial in the relief of patient's complaints as compared to laser partial mucosal palatal excision (LPMPE) . On the other hand LUPPP is considered as more difficult technique and creates more postoperative complications as compared to LPMPE. Therefore this study was conducted prospectively to compare both techniques regarding postoperative outcomes.

Materials and methods: 22 patients aged 27-55 years presented with simple and obstructive snoring. The patients evaluated locally and systemically including sleep study by modified polysomnography. The preoperative thyroid function test was performed for all cases to exclude the possible snoring predisposition by hypothyroidism status. The patients were divided into two groups, group-A which included thirteen patients and operated by LUPPP, group-B in which patients operated by LPMPE. The both groups compared in relation to operative time consumption, intra operative bleeding, postoperative dysphagia and odynophagia, postoperative oral intake, vomiting tendency, referred otalgia, fever, otitis media, septicemia, airway obstruction, the period of postoperative hospitalization and healing process,postoperative foreign body sensation, postoperative velopharyngeal insufficiency, and persistence or recurrence of snoring postoperatively.

Results: $80 \%$ of patients at group-B showed nonsignificant intra operative and postoperative bleeding, non-significant postoperative dysphagia, odynophagia, referred otalgia, fever, and vomiting tendency as compared to group-A with percentage of $37 \%$ who showed same results. all patients of group-A stayed more than $24 \mathrm{~h}$ postoperatively at hospital as compared to group-B in which $80 \%$ of patients stayed

\section{DIFFERENT VARIETIES OF LASER SURGICAL PROCEDURES FOR MANAGEMENT OF SNORING PATIENTS WITH UVULAR ABNORMALITIES \\ Khaled Mohamed Bofares}

Associate Professor Otorhinolaryngology Dept, Omar Almoukhtar University, Elbyda, Libia

Background and objectives: Recently by improvement of the education levels of general populations the snoring has been considered as one of common presented problems at otorhinolaryngeology departments which may interfere with normal personal social life thus the research for optimum procedures to resolve this problem become one of the priorities at this specialty. Although snoring can be due to functional predisposition but still the obstructive verity of snoring is commonest. This obstruction can occur at different levels starting from nose up to oropharynx with variable degrees of obstruction severity. The uvula is considered as one of the common structures of upper air way tract which may develop certain anatomical abnormalities resulting in upper air way obstruction. In the same time it is claimed that interference with the uvula by recommended procedures including $\mathrm{CO} 2$ laser surgical procedures may effectively help in management of this problem. Therefore this study was conducted prospectively to assess whether there is any significant difference between these variable uvular related laser procedures from the out comes point of view regarding relief of snoring as well as from the post operative complications point of view.

Patients and methods: Twenty-eight patients aged 2755 years presented at ENT department -Althowra central hospital - elbyda - Libya with history of snoring which disturbs the normal social life of those patients and through the local clinical examination there were four varieties of local uvular related findings via which the received patients were divided into four groups, group-A which was including the patients with long uvula associated with enlarged tonsils and palatal flutter who underwent laser uvulopalatopharyngoplasty (LUPPP) and the number of patients at this group was 13 cases, group -B which was including five cases who were presented with elongated and webby uvula those patients operated by laser assistant uvuloplasty (LAUP), while other five cases were included at group-C with local presentation constituted by elongated uvula only who proceeded by what is called laser uvular flap procedure (LUFP), and the last group was group-D which was including five cases too and those patients were presented locally by elongated uvula, uvular webbing as well as hypertrophied palatine tonsils, those patient were interfered by the modified laser uvular flap procedure (MLUFP). All patients were evaluated preoperatively by modified sleep study, thyroid function test, chest imaging, ECG, body-mass index measurements as well as all routine blood tests. In addition all patients were followed up for 6 months postoperatively to confirm the degree of improvement in snoring and to elucidate for any post procedure complications development.

Results: Regarding the snoring, all patients at all four groups showed significant postoperative improvement in snoring. $80 \%$ of patients at group-A showed nonsignificant intra operative and postoperative bleeding, non-significant postoperative dysphagia, odynophagia, referred otalgia, fever, and vomiting tendency as compared to other three groups where all patients showed same results. All patients of group-A stayed more than $24 \mathrm{~h}$ postoperatively at hospital as compared to group-B in which $60 \%$ of patients stayed less than $24 \mathrm{~h}$ at the 
hospital after surgery while $65 \%$ of patients in both group-C and D who showed same results. On the other hand $15 \%$ of patients in group-A developed postoperative foreign body sensation and velopharyngeal insufficiency as compared to other groups at which no patient was presented with this kind of complications. One patient of group-A was presented with recurrence of snoring after 3 years from the surgery. Regarding otitis media, airway obstruction and septicemia, in all four groups no cases were registered. The healing process as sequel of all procedures completed by 1 week.

Conclusion: Generally speaking uvula constitutes one of important anatomical structures at upper air way tract which plays very significant rule in pathogenesis as well as management of snoring. There are different varieties of laser surgical procedures which can be used to treat uvular related snoring. The selection of the proper procedure is depending up on many local as well as systemic factors. The proper selection of optimum procedure will determine the degree of intervention succeeds.

MILESTONES IN THE EVOLUTION OF ENDOSCOPY: A SHORT HISTORY WITH SPECIAL EMPHASIS ON SIALOENDOSCOPY

Oded Nahlieli DMD ${ }^{1}$, Ohad Baruchin $\mathrm{MD}^{2}$ and Abe $\mathrm{M}$. ${\text { Baruchin } \mathrm{MD}^{3}}^{3}$

${ }^{1}$ Professor and chairman, Department of Oral \& Maxillofacial Surgery, Barzilai University Medical Center Ashkelon, Israel ${ }^{2}$ Department of Ob/Gyn, Assaf Harofeh University Medical Center, Zerifin.Israel

${ }^{3}$ Professor, Chief of the Laser Unit, University Barzilai Medical Center Ashkelon, Israel

Although the fundamental ideas that form the basis for modern endoscopic surgery were reported over a century ago, the practical incorporation of the technique into the fields of surgery has been a relatively recent development., Albukasim (936-1013 A.D.), and later, Phillip Bozzini in 1805 ,were among the first to develop methods to examine body orifices. It was not until 1853 that the first effective open tube endoscope was invented by Desormeaux. In the late 1800 's, several physicians including Kussmaul and Nitze refined the endoscopes. Endoscopically examinining the peritoneal cavity was first attempted in 1901 by George Kelling.In the early 1930's, the first reports of laparoscopic interventions for nondiagnostic purposes were published. During the 1960's and 1970's, laparoscopy became a vital part of gynecological practice. In 1986, following the development of a video computer chip for projection of images onto television screens, the techniques of endoscopic surgery truly became integrated into the discipline of surgery. The French physician Mouret performed in 1987 the first laparoscopic cholecystectomy on a human patient. The rapid acceptance of the technique of endoscopic surgery has changed the face of surgery more drastically and rapidly than any other surgical milestone and is unparalleled in surgical history. This presentation illustrates the history behind this exciting surgical technique with special emphasis on sialoendoscopy.

\section{INNOVATIVE GRID POSITIONING SYSTEM (GPS) FOR ENDOSCOPIC LASER TRANSFORAMINAL MICRODECOMPRESSIVE LUMBAR DISC SURGERY IN THE MORBID OBESE}

\section{J. Chiu, MD}

California Spine Institute, Laser Neurospine Surgery

Thousand Oaks - USA

chiu@spinecenter.com

Introduction: Morbid obesity is characterized by an individual having a body mass index (BMI) of 40 or higher. The morbidly obese patient poses many unusual surgical/anatomical challenges during endoscopic laser minimally invasive spine surgery (MISS), especially to target the lesion with precision and accuracy through a surgical portal of entry. The problem that faces the surgeon performing MISS is that it is done with limited surgical exposure and visualization of the surgical field.

Methods: In response a logical and simple Grid Positioning System (GPS) was developed to provide a precise surgical trajectory/approach for the disc lesion to undergo decompression. GPS involves 3D geometric triangulation of 3 different planes guided by fluoroscopy for introduction of surgical instruments along a geometric line toward the lesion without compromising healthy anatomical structures. This system facilitates laser MISS, especially in the morbidly obese.

156 morbidly obese surgical patients with 254 intractable symptomatic herniated lumbar discs underwent endoscopic MISS, guided by GPS.

Results: Overall result $90 \%$ patients with good to excellent results. Fair results $6.4 \%$ patients, for single level, average satisfaction score is $93 \%$.

Conclusion: Applying the concept of Grid Positioning System (GPS) to laser MISS can help the surgeon to facilitate the MISS process by quickly identifying the surgical portal of entry to the disc without compromising vital anatomical or neur al structures and accomplish needed spinal microdecompression, especially in medically high-risk patients including the morbidly obese and even those with prior surgeries. It can be very effective in surgical treatment of degenerative spine and herniated lumbar discs condition. 


\section{LASER ENDOSCOPIC ANTERIOR CERVICAL DISCECTOMY/FORAMINOPLASTY WITH INTRAOPERATIVE \\ NEUROPHYSIOLOGICAL MONITORING (IOM)}

J. Chiu, MD, PhD

California Spine Institute, Laser Neurospine Surgery,

Thousand Oaks, USA

chiu@spinecenter.com

Introduction: To demonstrate outpatient laser endoscopic anterior microdecompressive cervical discectomy and foraminal decompression (foraminoplasty), by utilizing GPS (grid positional system), can treat herniated cervical discs and cervical foraminal stenosis efficaciously and successfully.

Materials and Methods: Since 1995, 2066 patients (3730 Discs), who failed at least 12 weeks of conservative care were treated, with radicular pain of a specific dermatome, single level or multiple levels, confirmed with EMG/NCV. MRI or CT scans with herniated cervical disc. The surgical technique of anterior endoscopic microdecompressive cervical discectomy foraminal decompression (foraminoplasty) and laser thermodiskoplasty (non-ablative lower Holmium laser energy for disc shrinkage and tightening) is performed under intraoperative neurophysiological monitoring (IOM) and is guided and facilitated with GPS.

Results: For single level, 94\% had good to excellent symptomatic relief and spinal motion preservation. $6 \%$ of patients had some persistent neck and upper extremity residual but diminished pain associated with parasthesia, after surgery. Average time to return to work was 10 14 days. There were no intraoperative complications. Postoperatively, one with transient Horner's syndrome and one transient hoarseness voice were noted.

Conclusion: Laser endoscopic anterior microdecompressive cervical discectomy and foraminal decompression and lower level non-ablative Holmium laser for disc shrinking and tighten ing effect (laser thermodiskoplasty) with IOM and GPS, proved to be safe, less traumatic, easier, and efficacious with significant economic savings. It preserves spinal motion.

\section{LASER MINIMALLY INVASIVE SPINE SURGERY (MISS): A SURGEON'S PERSPECTIVE ON TECHNOLOGICAL CONVERGENCE AND DIGITAL OR CONTROL SYSTEM}

\section{J. Chiu, MD}

California Spine Institute, Laser Neurospine Surgery

Thousand Oaks - USA

chiu@spinecenter.com

Introduction: Degenerated lumbar disc and spinal stenosis are common problems requiring decompressive lumbar surgery. Open spinal discectomy is associated with significant trauma, morbidity, long-term convalescence, prolonged general anesthesia and wide dissection of tissues that can cause bleeding, scarring and eventual destabilization of spinal segments. The less traumatic endoscopic laser MISS is free from these potential complications.

Methods: The endoscopic laser spine surgical procedure, its surgical indications and its operative techniques including laser tissue modulation technology are presented. It requires seamless connectivity to perform the surgical procedures, Surgical ePR Control System (SECS), SurgMatix ${ }^{\circledR}$, a new integrated image-data based OR control system has been developed and utilized to facilitate this laser MISS and creates organized control instead of organized chaos.

Results: Among a series of 5336 laser MISS patients $(10,255$ discs $)$ the surgical result for laser MISS has been extremely gratifying for both the patient and the surgeon. There was no postoperative mortality, and morbidity of less than $1 \%$. The potential risk and potential complications are presented. Endoscopic microdecompression can effectively decompress herniated discs and treat spinal stenosis with foraminoplasty.

Conclusion: Laser MISS can effectively decompress herniated discs and spinal stenosis with foraminoplasty for treatment of spinal stenosis. It also provides an excellent and effective access or platform for spinal arthroplasty and others. Obviously, this outpatient laser endoscopic MISS leads to excellent results, faster recovery, and significant economic savings.

\section{LASER THORACIC ENDOSCOPIC MICRODISCECTOMY WITH GPS SYSTEM}

\section{J. Chiu, MD, PhD}

California Spine Institute, Laser Neurospine Surgery, Thousand Oaks, USA

chiu@spinecenter.com

Introduction: To demonstrate the safety and efficacy of outpatient based endoscopic thoracic discectomy with laser thermodiskoplasty performed for symptomatic thoracic herniated nucleus pulposus.

Materials and Methods: Since February 1996, 412 patients' (516 discs) with symptomatic thoracic discs without myelopathy, who failed at least 12 weeks of conservative care, were treated. The technique of percutaneous microdecompressive endoscopic thoracic discectomy (with laser thermodiskoplasty) with GPS (Grid Positioning System) by posterolateral approach is described. The thoracic disc levels were T1 to T12. All patients demonstrated a contained soft thoracic disc herniation on MRI or CT scans. Intraoperative thoracic discogram and pain provocative tests were positive and confirmed the disc involved. 
Results: Preliminary postoperative follow-up demonstrates $90 \%$ of all patients had good to excellent and $6 \%$ fair symptomatic relief. The average time to return to work was 10 days for the non-workers' compensation patients. Most of the patients received non-ablative lower laser energy application for thoracic disc shrinkage or tightening.

Conclusion: Laser microdecompressive endoscopic thoracic discectomy with GPS (Grid Positioning System) and application of non-ablative lower Holmium laser energy for disc shrinkage (laser thermodiskoplasty) appears to be easy, safe and efficacious. This less traumatic, easier outpatient treatment leads to excellent results, faster recovery, and significant economic savings.

\section{SACROILIAC JOINT PAIN SYNDROME: ANATOMY DIAGNOSIS AND TREATMENT - SURGICAL LASER THERMONEURECTOMY}

\section{J. Chiu, MD}

California Spine Institute, Laser Neurospine Surgery

Thousand Oaks - USA

chiu@spinecenter.com

Introduction: Sacroiliac Joint (SIJ) pain contributes up to $25 \%$ of patients with low back pain. $25-39 \%$ of patients with SIJ pain found to have low back pain. If the SIJ become symptomatic, it may cause pain in the low back, buttocks, abdomen, groin or legs. Currently there is no standard treatment algorithm

Methods: The innervation of the SIJ is extremely complex, mostly believed to be: posterior innervation from medial branches of dorsal rami of spinal nerves, L4, L5, S1-3. Anterior innervation: The L4-S2 ventral rami. Pain in the region of SIJ with possible radiation to the groin, medial buttock and posterior thigh. Diagnostic reproduction of pain by physical examination technique that stresses the joint.

If conservative medications, physical therapy, and acupuncture fail then:

- SIJ injections intra-articular and extra-articular

- If above fails and SIJ pain continues then:

- Nerve blocks L4 to S3 can be performed if pain continues,

- Laser thermoneurectomy/rhizotomy for denervation is performed with endoscopic microdecompression laser neurolysis with lower level Holmium YAG laser.

Results: In 34 patients, average follow-up 24 months (12 months). Overall result: 31 (91\%) patients with good to excellent results, fair results $3(8.8 \%)$. Average satisfaction score - 32 (94\%) patients. Surgical complication: 0\% Conclusion: SIJ pain can often be treated conservatively. If failure of conservative treatment it can be successfully treated with laser thermoneurectomy (LTN), which appears to be a safe and efficacious outpatient procedure.
PERCUTANEOUS LASER LUMBAR INTERVERTEBRAL DISC-DECOMPRESSION

\section{G. Terbetas, D. Varanius, A. Vaitkuviene}

Clinics of Neurology and Neurosurgery, Vilnius University Hospital \& Institute of Applied Research, Vilnius University, Lithuania

Background: We present surgical treatment results for intervertebral disc hernia- Percutaneous Laser Disc Decompression (PLDD) and disc spectral diagnostics proposal at point of care.

Purpose: Optimisation of disc decompression indications by straight photo diagnosis.

Material and Methods: All 20 patients preoperatively were evaluated by Visual Assessment Analogue Scale (VAS) and Oswestry Disability Index (ODI). Spectral and immunohistological investigation of 29 patient disc specimen from open operations was performed by means of portable $355 \mathrm{~nm}$ microlaser STA-01-TH (Standa, Ltd.), and AvaSpec-2048TEC spectrometer.

Results: 14 patients (70\%) experienced long lasting relief of their symptoms. At 6 month follow-up VAS score changed from (mean) 5.0 to 1.75), at movement from (mean) 6,75 to 2.6 points. Mean VAS drop was 3.25 points at resting state, and 4.15 points at movement. Mean ODI drop was $28.7 \%$. Statistical differences of spectral component were found in disc periphery ( $\mathrm{P}$ group - herniation removed from subligamentous space), tissue with different level of BOOS index

Discussion and Conclusion: Surgical treatment provides faster rehabilitation and faster de $\neg$ crease of symptoms, but has a certain danger of late complications. PLDD has been recently accepted as effective surgical intervention on certain types of disc herniation. Open microdiscectomy and PLDD should not be compared as two different ways of treating the same patient because inclusion criteria for both methods differ due to morphology of disc herniation on MRI. Patients having moderate or mild protrusion of intervertebral disc with no obvious compression of nerve roots should go for PLDD. Spectral diagnosis in situ is potential for personalized medicine approach in disc minimal invasive treatment.

\section{FABRICATION OF ADHESIVE BIOGLASS/POLYESTER SCAFFOLDS FOR SPINAL DISK DEFECTS}

A. Lauto ${ }^{1}$, M. Mnatsakanyan ${ }^{1}$,S. Piller ${ }^{1}$, D. Mawad ${ }^{2}$, L. Longo ${ }^{3}$, P. Boughton ${ }^{4}$

${ }^{1}$ University of Western Sydney

${ }^{2}$ University of Wollongong

${ }^{3}$ University of Siena

${ }^{4}$ University of New South Wales a.lauto@uws.edu.au

Biocompatible scaffolds, made of Bioglass, are currently used in tissue engineering to repair bone and cartilage 
defects. The main advantages associated with their application are tissue growth and remodelling, availability (non autologous tissue), and in situ drug delivery. The anchoring of these scaffolds on tissue can be problematic because sutures or staples are currently employed. Such techniques are invasive for the host tissue and scaffold and can result in complications for the patient.

The aim of this study was to integrate a chitosan-based adhesive with a bioresorbable bioglass/polyester scaffold (Variotis ${ }^{\mathrm{TM}}$ ) and to anchor it to tissue without sutures. The adhesive-scaffold was bonded in in vitro using sheep tissue and a computer interfaced tensiometer measured the adhesion strength. The adhesive was activated by a green laser $(l=532 \mathrm{~nm}$, spot size $\sim 4 \mathrm{~mm}, P=0.180 \mathrm{~mW}$, Fluence $\sim 110 \mathrm{~J} / \mathrm{cm}^{2}$ ) that increases the bonding tissue strength upon irradiation. The bonding mechanism between the chitosan adhesive and tissue relied on photochemical reactions and it did not cause any significant temperature increase $\left(\sim 35^{\circ} \mathrm{C}\right)$. Murine fibroblasts were also cultured on the chitosan-scaffold to assess any possible cytotoxic effect.

The chitosan adhesive was successfully integrated with the scaffold and adhered firmly to tissue upon laser irradiation $(\sim 15 \mathrm{kPa}, n=15)$. Fibroblats grew on the adhesive-scaffold without any apparent morphological change, when compared to control cells.

\section{INTERFERENTIAL LASER THERAPY IN THE RELIEF OF PAIN IN THE CARPAL TUNNEL SYNDROME. A PILOT STUDY}

Ramon Montes-Molina, Maria Elena MartinezRodriguez, Almudena Prieto-Baquero, Blanca PalominoAguado, Susana Lopez-Serrano, Ignacio Regidor-BaillyBailliere, Berta Collantes-Panero, Rosa Aliaga-Casto, Maria Jesus Gutierrez-Garcia, Fidel Martinez-Ruiz

Hosp. Univ Ramón y Cajal.IRYCIS.Unit of Clinical Electrotherapy, Department of Physical Medicine and Rehabilitation. Department of Neurology. Unit of Occupational Therapy. Department Orthopaedic Surgery - Madrid, Spain

Background: Interferential laser therapy consists in the generation of a laser interference pattern into the treatment area and has shown safety and feasibility in treating knee and shoulder pain.

Purpose: To describe the effect of interferential laser therapy procedure in the treatment of carpal tunnel syndrome (CTS) focusing on the median nerve irradiation. Materials and Methods: A total of 20 patients with CTS diagnosed based on electroneurography received interferential laser therapy generated by two identical diode lasers (AsGaAl, $808 \mathrm{~nm}, 100 \mathrm{~mW}$ ) placing probes opposite each other transcutaneously on 7 points per session $(5 \mathrm{~J} /$ point/ probe) over distal median nerve branches at wrist and hand. Main outcome measures were items 1, 2, 3, 4 and 5 from Boston Carpal Tunnel Syndrome Symptom Severity Scale that were evaluated before and after treatment.

Results: 20 patients with a severity were mild and with an average duration of symptoms of 36 months. The affected wrist left/right was $8 / 12$. There were significant changes using the Wilcoxon test two-tailed for the intensity nocturnal pain $(Z=-2.066 ; p=0.039)$; Intensity diurnal pain: $Z=-2.081$; $p=0.037)$ and frequency diurnal pain: $Z=-2.236$; $p=0.025$ ). There were no significant changes for the frequency of nocturnal pain: $Z=-.333 ; p=0.739$ ) and for the duration of diurnal pain: $Z=-1.633 ; p=0.102$ ).

Discussion and Conclusions: Interferential laser therapy was effective in the short-term reduction of nocturnal and diurnal pain of carpal tunnels yndrome of mild severity in pre or post surgical patients. The observed positive findings could be used to design future clinical trials to test the effectiveness of this procedure.

\section{GaAIAs LASER DIODE LASER - TEMPOROMANDIBULAR JOINT REHABILITATION}

P. Hlinakova, T. Dostalova, V. Navratil, E. Blazkova, L. Navratil

Charles University $2^{\text {nd }}$ Medical Faculty, Department of Paediatric Stomatology, Prague, Czech Republic; Charles University $1^{\text {st }}$ Faculty of Medicine, Institute of Biophysics and Informatics, Prague, Czech Republic; CVUT - Faculty of Biomedical Engineering, Kladno, Czech Republic; THERAP-THILIA, Department of Physiotherapy, Prague, Czech Republic

Background: A multifactorial etiology of temporomandibular joint disorders (TMD) is proposed. $20 \%$ of the population is affected. 10-20\% is seeking treatment.

Purpose: Physical therapy is being used in the treatment of TMD because of its analgesic, myorelaxing, antiinflammatory and stimulating effects. The goal of the study was to decrease the pain in the area of TMJ.

Material and Methods: Group of 103 patients was treated (17 men (average age 18.57 years), 87 women (average age 27.57 years). Multidisciplinary physical therapy including low level laser was used. Laser parameters were: GaAlAs laser diode $-830 \mathrm{~nm}$; output power $400 \mathrm{~mW}$; probe aperture: $0,2 \mathrm{~cm} 2$; energy density $15 \mathrm{~J} / \mathrm{cm} 2$; time $11 \mathrm{~s}$; frequency continuous; kind of application contact; number of treatment sessions -5 . Average length of treatment was from 9.45 months (women) to 11.58 months (men).

Results: Control examination evaluated the therapy. Subjective: The reported pain by patient on VAS decreased from 20 to 5. Clinical examination: Patients did not 
reported any tenderness of the TMJ and masticatory muscles during clinical examination.

Discussion and Conclusion: The effectiveness of the low level laser for TMD has been proved not only by significantly better therapeutical results in the patients treated with the GaAlAs laser diode Laser, but also in the patients with chronic pain and in those who did not respond to previous other conservative methods used for the treatment of TMD.

\section{EVALUATION OF LED PHOTOBIOMODULATION ON WOUND HEALING IN HYPOTHYROID AND EUTHYROID RATS}

GM Paraguassúa ${ }^{\text {, FCA } \text { Xavier }^{\mathrm{b}} \text {, TT Rodriguez }}{ }^{\mathrm{c}}$, MJP Ramalho $^{c}$, ALB Pinheiro ${ }^{\mathrm{a}, \mathrm{d}, \mathrm{e}}$, LMP Ramalho ${ }^{\mathrm{a}, \mathrm{b}}$

${ }^{a}$ Center of Biophotonics, School of Dentistry, Federal University of Bahia, Salvador, Bahia, Brazil

${ }^{b}$ Laboratory of Surgical Pathology, School of Dentistry, Federal University of Bahia, Salvador, Bahia, Brazil

${ }^{\mathrm{c}}$ Department of Physiology, Instituto de Ciências da Saúde, Federal University of Bahia, Salvador, Bahia, Brazil

${ }^{\mathrm{d} U n i v e r s i t y ~ o f ~ C a m i l o ~ C a s t e l o ~ B r a n c o, ~ S a ̃ o ~ J o s e ́ ~ d o s ~}$ Campos, São Paulo, Brazil

${ }^{\mathrm{e}}$ National Inst of Optics \& Photonics, Phys Inst., São Carlos, São Paulo, Brazil

Thyroid hormone deficiency has been associated to disruption of the body's metabolism, including healing process. LED phototherapy has been shown to be effective in improving healing in many situations, but their usefulness in the improvement of hypothyroidism wound healing remains unknown. The aim of this study was to assess histologically the effect of LED (InGaAlP, $\lambda 630 \mathrm{~nm}$, $150 \mathrm{~mW}, \mathrm{CW}, \phi 0.5 \mathrm{~cm}^{2}, 24 \mathrm{~J} / \mathrm{cm}^{2}$ per session) on wounds healing in hypothyroid and euthyroid Wistar rats. Standard cutaneous wound $\left(1 \mathrm{~cm}^{2}\right)$ was created on the dorsum of 24 animals divided into four groups of 6 animals each: G1: Euthyroid; G2: Euthyroid + LED; G3: Hypothyroid; G4: Hypothyroid + LED. Hypothyroidism was induced in rats with propylthiouracil $(0,05 \mathrm{~g} / 100 \mathrm{~mL})$ administered orally for 4 weeks and maintained until the end of the experiment. The irradiation started immediately after surgery and was repeated every other day for 7 days. Animals were killed 8 days after surgery. The specimens were removed, routinely processed and stained with H\&E and Picrosirius. Statistical analysis was performed using the Fisher's Test and significance level was $5 \%$. The results of the present investigation showed delayed wounds healing process in hypothyroid rats characterized by incomplete reepithelialization, reduced thickness of epithelial layers and formation of disorganized collagen fibers (Fisher, $p<0,05$ ) when compared to the euthyroid group. There was histological evidence of improved amount of collagen fibers on irradiated animals (euthyroid and hypothyroid) when compared to non irradiated ones (Fisher, $p<0,05$ ). It is concluded that LED has a positive biomodulative effect on the wound healing process, even when hipothyroidism was present.

\section{ASSESSMENT OF THE EFFECTS OF LASER OR LED PHOTOBIOMODULATION ON HYPOTHYROID RATS OF CUTANEOUS WOUND HEALING: A MORPHOMETRIC STUDY. \\ De Castro, I.C.V.; Paraguassú, G.M.; Reis Júnior, J.A.; Xavier, F.C.A.; Rodriguez, T.T.; Ramalho, M.J.P.; Pinheiro, A.L.B.; Ramalho, L.M.P. \\ Federal University of Bahia, Faculdade de Odontologia, Salvador, Brazil}

Thyroid hormone deficiency (THD) has been associated to the disruption of the body's metabolism including healing process. Laser and LED have been shown to be effective by improving healing in many situations, but their usefulness in the improvement of hypothyroidism healing wound remains unknown. The aim of this study was to assess morphometrically the influence of Laser (GaAlAs, $\lambda 660 \mathrm{~nm}$, $24 \mathrm{~J} / \mathrm{cm}^{2}, 40 \mathrm{~mW}, \mathrm{CW}$, f $4 \mathrm{~mm}^{2}$;) and LED(InGaAlP, $\lambda 630 \mathrm{~nm}, 24 \mathrm{~J} / \mathrm{cm}^{2}, 150 \mathrm{~mW}, \mathrm{CW}, \mathrm{f} 0,5 \mathrm{~cm}^{2}$ ) on wound healing process on rats with THD. Under general anesthesia a standard surgical wound $\left(1 \mathrm{~cm}^{2}\right)$ was created on the dorsum of 72 male Wistar rats divided into 6 groups of 12 animals each: G1: Euthyroid; G2: Euthyroid + Laser; G3: Euthyroid + LED; G4: Hypothyroid; G5: Hypothyroid + Laser and G6: Hypothyroid + LED. Hypothyroidism was induced in rats with propylthiouracil $(0,05 \mathrm{~g} / 100 \mathrm{~mL})$ administered orally for 4 weeks and maintained until the end of the experiment. Rats were irradiated after surgery and every each $48 \mathrm{~h}$ following sacrifice at 7 and 14 days. Statistical analysis was performed using the Mann-Whitney non-parametric method. Hypothyroid rats with no phototherapy had less wound cicatricial contraction than euthyroid rats only in the period of 14 days $(p=0.025)$. There was significant difference between euthyroid and hypothyroid rats treated with Laser and LED, especially in 7 days regarding to macroscopic analysis of wound contraction ( $p=0,037$ and $p=0,025$ ). The results suggest that the use of Laser and LED improve wound healing on hypothyroid animals at both early and late stages of repair.

HEMANGIOMA TREATMENT EFFECT OF PDL, ALEXANDRITE, ER: YAG AND CO2 LASERS Eva Remlova $^{1}$, Tatjana Dostalova ${ }^{2}$, Helena Jelinkova ${ }^{3}$, Jana Vranova $^{3}$, Leos Navratil ${ }^{4}$, Jozef Rosina ${ }^{4}$ 
${ }^{1}$ AVE LASER CENTRUM, Olomouc, Czech Republic; ${ }^{2}$ Charles University, $2^{\text {nd }}$ Medical Faculty, Department of Paediatric Stomatology, Prague

${ }^{3}$ Czech Technical University in Prague, Faculty of Nuclear Sciences and Physical Engineering, Prague

${ }^{4}$ Czech Technical University in Prague, Faculty of Biomedical Engineering, Kladno, Czech Republic

Background: Hemangioma is a mesenchymal benign tumor formed by blood vessels. Anomalies affect up to $10 \%$ of children and they are more common in females than in males.

Purpose: The aim of the study was to evaluate hemangioma treatment using four different types of lasers namely Alexandrite, Erbium: YAG, CO2 and PDL.

Material and Methods: The group of 869 patients with hemangioma was retrospectively reviewed. Patients included in our study were divided into four groups according to the type of laser used. All patients were treated in one session without anesthesia application. The ablative systems vaporized the tissues until the hemangioma was removed. The non-ablative systems used one shot which destroyed the hemangioma blood vessels.

Results: For the treatment efficacy analysis, the following factors were evaluated: therapeutic effect (yes vs. no), loss of pigment (yes vs. no), and appearance of scar (yes vs. no). From results it was evident that the therapeutic effect of all the lasers except Alexandrite was very high - almost 100\%. In the $\mathrm{CO} 2$ and the ER: YAG laser also the high percentage of side effects was observed. The exposure of these lasers caused loss of pigment and scar formation in many cases. The best therapeutic effect, with only minor side effects has been reached by the PDL laser.

Discussion and Conclusion: It was confirmed that PDL (595 nm, $1.5 \mathrm{~ms}, 7 \mathrm{~mm}, 9-11 \mathrm{~J} / \mathrm{cm}^{2}$ ) had the optimal effect without scars. Er: YAG or $\mathrm{CO} 2$ laser radiation was also useful for small superficial lesions.

\section{RAMAN IMAGING FOR THE IDENTIFICATION OF BREAST CANCER CELLS}

J.L.Gonzales ${ }^{1}$, G.H. Luévano-Colmenero ${ }^{2}$, J. VargasMancilla $^{2}$, I. A. Arana-Zamora ${ }^{2}$, J. C. Martínez-Espinosa ${ }^{2}$

${ }^{1}$ Centro Universitario de los Lagos, Universidad de Guadalajara

${ }^{2}$ Instituto Mexicano del Seguro Social

Raman Imaging provides the spatial distribution of the various molecular species within the cell, making it possible to produce fast and accurate chemical images without the use of stains, dyes and without destroying the sample. Raman imaging allows investigation the location of breast cancer cells within the cell culture sample where a distinctive Raman signal may originates. The tumor biopsies were obtained from patients who were clinically diagnosed with breast cancer. Breast cancer cells isolated from the biopsy were washed, centrifuged and seeded out. Cultivation took place in DMEM. Immediately the washed cells were analyzed in phosphate buffered saline (PBS) at pH 6. Raman analysis was carried out on the Jobin-Yvon LabRAM HR800 microscope system, with a NIR $830 \mathrm{~nm}$ laser excitation source. A typical collection time of $1 \mathrm{~s}$ was used to acquire good quality spectra. Mapping was carried out over a $100 \mu \mathrm{m} \times 100 \mu \mathrm{m}$ region with $1 \mu \mathrm{m}$ step and full two-dimensional image is obtained. Observed spectral features differed across the cell, but species such as the nucleotides thymine, adenine and guanine, and amino acids tyrosine and phenylalanine can be identified. The preliminary results suggest that Raman imaging could be a new technique for the identification of breast cancer cell.

\section{LASERTHERAPY IN POSTPARTUM VAGINAL ATROPHY}

\section{Daniela Brinzan, Lucian Paiusan}

Hospital of Obstetrics and Gynecology Arad, Romania

brinzan_daniela@yahoo.com

Somebody said that a woman needs nine months to become a mother and other nine months to become a woman again, which is perfectly true. Giving birth to a child is one of the most complex events in the experiences of humans and perhaps the most difficult thing for a woman who has become a mother is restarting her sexual life. The aim of this study is to prove the role of laserotherapy (LT) compared to local trophics therapy in postpartum vaginal atrophy, and obviously, in restarting sexual function. From a total of 60 patients in our medical records, who gave birth in the period between January 2010 and January 2011, 40 have been studied. The methods employed to objectify vaginal atrophy and to evaluate sexual activity have been:

- Anamnesis (questionnaire)

- Local clinical examination

- Vaginal cytological exam

The 40 patients have been treated differentially, being included in four groups:

- patients with vaginal trophics

- patients with LT

- patients with associated treatment: vaginal trophics and LT

- patients without treatment.

Therapeutic benefit, improvement of vaginal atrophy and quality of sexual life were objectified by anamnesis 
(questionnaire), local clinical examination and vaginal cytological exam. The best results have been obtained with associated therapy immediately followed by unique LT. In conclusion, LT can be considered the best way to improve vaginal atrophy in postpartum period and obviously in restarting sexual life.

\section{A NEW MINIMAL INVASIVE LASER-ASSISTED TECHNOLOGY TO TREAT SKIN LAXITY, FAT AND CELLULITE}

Katharina Russe-Wilflingseder, Manfred Herold, Elisabeth Russe

Plastische Chirurgie und Laserzentrum Innsbruck, Austria

Background: Lasers are becoming more accepted for laserassisted lipolysis (LAL). Laser can disrupt adipose tissue as well as induce neocollagenesis associated with tissue tightening. Using lasers subdermally can also afford us the opportunity to treat cellulite. Cellulite is worsened by increased skin laxity, fibrotic septa and herniated fat. This presentation will focus on our experience with laserassisted lipolysis, skin tightening and treatment of cellulite. Methods: Since 3 years we are using LAL for treating skin laxity, lipodystrophy and cellulite on abdomen, thighs, upper-arms. 84 patients were operated; 65 with $1064 \mathrm{~nm}$ and $1320 \mathrm{~nm}$ (blended $1: 1$ or $1: 3 ; 12-46 \mathrm{~W}$ ) and 10 with $1440 \mathrm{~nm}$ and a new side firing fiber (10-12 W).We also treated 9 subjects with unwanted cellulite. Laser parameters and application time were adapted to size of area, thickness of skin and subcutaneous fat layer and fibrotic septae. Interstitial temperature control ensured efficient neocollagenesis and lipolysis. Laser energy was delivered homogenously in a fanning and criss-crossing technique. Procedures were performed in TLA and i.v. sedation as any conventional liposuction procedure. For LAL liquidized fat was aspirated and fluid was expressed. Postoperative compression garments were given for 2 weeks.

Results: In our experience of 3 years we saw that LAL due to thermal effect on collagen fibers has resulted in thickening and tightening of skin. Very superficial application can also disrupt the herniated fat cells and thermally subcise the septa associated with cellulite. The main advantage compared to traditional liposuction is tissue tightening, less swelling, bruising, pain and downtime. Highly satisfactory results were achieved. No severe side effects like scarring or infection were seen. Outcome was increasing continually up to 3-6 months.

Conclusion: LAL is effective and safe. Possibility of combining wavelengths increases the efficiency for tissue tightening and lipolysis and allows treating areas of skin laxity or adiposity with bad skin quality to improve the aesthetic outcome. The new $1440 \mathrm{~nm}$ wavelength with the sidefiring fiber gives us the possibility to treat cellulite

\section{PLACEBO CONTROLLED, PROSPECTIVELY RANDOMIZED, DOUBLE-BLINDED STUDY FOR THE INVESTIGATION OF THE EFFECTIVENESS AND SAFETY OF THE ACOUSTIC WAVE THERAPY (AWT ${ }^{\circledR}$ ) FOR THE CELLULITE TREATMENT Katharina Russe-Wilflingseder ${ }^{1}$, Elisabeth Russe ${ }^{1}$, Monika Drmic ${ }^{1}$, Johannes C. Vester ${ }^{2}$, Gerd Haller ${ }^{3}$, Pavel Novak ${ }^{3}$, Alexander Krotz ${ }^{3}$ \\ ${ }^{1}$ Plastische Chirurgie und Laserzentrum, Innsbruck, Austria \\ ${ }^{2}$ idv, Gauting, Germany \\ ${ }^{3}$ Storz Medical, Tägerwilen, Switzerland}

Background: Acoustic wave therapy (AWT) is a new approach to improve the appearance of cellulite. Pulses are penetrating into the tissue, stimulating tissue metabolism and blood circulation. Objective of this study is demonstrating efficacy and safety of AWT for cellulite.

Methods: Study was designed as placebo controlled double-blinded, prospectively randomized clinical trial to assess efficacy of AWT by combining superficial and deeper penetrating radial waves within 1 session. 15 females included: 11 verum, 4 placebo; BMI 22.7; age 42.5. 8 Tx given per week using D-Actor 200 (Storz Medical). Documentation and evaluation was done before, 1 week after 7th treatment and at week 4 and 12 after last treatment. Patients' questionnaire, weight control, measurement of circumference, standardized photography was evaluated. Results were documented by 3D imaging system. Surface topography parameters dealt as objective measure and used as primary efficacy criteria.

Results: Statistically significant improvement of cellulite in verums not in placebos between baseline and 3 month follow-up shown by 3D measurements in $\mathrm{Sq} p=0.028$ (improvement waviness skin surface - height and depth of dimples), Sz $p=0.002$ (improvement depth of dimples) and $\mathrm{Vvv}+\mathrm{Vmp} p=0.019$ (improvement volume depressions and elevations). Overall result based on Multivariate Wilcoxon Test indicates a more than medium sized superiority (MW= $0.6706)$ of verums vs. placebos and is statistically significant (PWei-Lachin=0.0106). Patient's questionnaire revealed improvement in number and depth of dimples, skin firmness and texture, little change in shape and reduction of circumference .Patients' average rating of treatment success stated only for verums a constant improvement at all follow-ups

Conclusion: This study could verify efficacy of superficial and deeper penetrating radial acoustic waves in treating cellulite. As primary efficacy criteria of results measure- 
ments of surface topography parameters were used as this is seen as objective measurement of cellulite. Only in verums significant improvement of cellulite was seen.

SYRINGE-ASSISTED NECK LIPOSUCTION ALONE AND IN COMBINATION WITH LOW INTENSITY LASER LIPOLYSIS FOR SKIN TIGHTENING Misbah Khan $^{1}$ MD, Tiffany Turner ${ }^{2}$ RN, Murad Alam ${ }^{2}$ MD

${ }^{1}$ Weill Cornell Medical College, New York, USA

${ }^{2}$ Northwestern University, New York, USA

Background: Neck liposuction is frequently performed in patients with pre-platysmal fat, good skin quality and absence of platysma bands. Patients with poor skin quality may not be appropriate candidates for neck liposuction.

Objective: To determine the quality and efficacy of low intensity laser lipolysis after syringe-assisted neck liposuction and its role in skin tightening in patients with skin laxity

Material and Methods: 20 adult healthy women ranging in age from 35 to 60 seeking neck liposuction were treated with either syringe-assisted liposuction alone or in combination with low intensity laser lipolysis based on their skin quality. No platsmaplasty was performed in addition to these procedures.

The choice of either of the procedures was based on the surgeon's assessment of the per-platysmal fat, bands and presence of absence thereof skin laxity.

Results: Patients with good skin quality age 50 showed significant skin retraction when syringe-assisted liposuction was followed by low intensity laser lipolysis at 3 month follow up visit.

One subject had a minor skin scab formation after the laser lipolysis. No other adverse effects were noted immediately after or at 3 month follow up

Conclusion: Syringe-assisted liposuction is a safe and quite efficacious procedure for patients seeking neck liposuction and mild skin tightening. However, when combined with low intensity laser lipolysis, can produce significant skin tightening in patients with skin laxity without the need for platysmaplasty.

THE COMBINED SURGICAL AND LASER TREATMENT OF THE GIANT PORT-WINE STAIN MALFORMATION-CASE REPORT

P. Drozdowski, MD, Siewiera Ireneusz, MD, PhD, Wójcicki Piotr, MD, PhD.

Department of Plastic and Reconstructive Surgery in Polanica Zdrój, Wrocław Medical University
Background: Port-wine stains (PWS) are vascular malformations of the skin concerning about $0,3 \%$ of the population. Though various laser systems have been used for various treatment regimens the treatment of PWS of large size is especially difficult and demanding from aesthetic and psychological point of view.

Purpose: The aim of the study was to evaluate the results of combined treatment of a patient presenting PWS covering about $45 \%$ of total body area.

Material and methods During the period of 2005-2011 we have treated a patient with a PWS covering about $45 \%$ of his body area. We started the laser treatment from the most exposed areas of the face and hands by 53 sessions with KTP $532 \mathrm{~nm}$ laser. During the treatment we also performed a surgical procedure of lower lip reduction and correction. Results: Significant improvement which was found very satisfactory for patient was reported. Treatment effect on the face evaluated on the basis of a computer program comparing $\mathrm{L}^{*} \mathrm{a} \mathrm{b}^{*}$ color coordinates of the lesion before and after treatment was $64 \%$. No laser nor surgical procedure side effects were observed.

Discussion and conclusion: Although complete clearance is hardly ever achieved, most patients report improvements in term of self esteem, contacts with the opposite sex and general well-being.

Laser and surgical treatment of giant PWS malformation is effective, safe and may be considered as the best modality for those type and size of vascular malformations.

Keywords: giant port wine stain malformation, vascular malformations, KTP $532 \mathrm{~nm}$ laser

\section{LASER SCAR REVISION}

Khalil A. Khatri, M.D.

New England Institute of Laser Research

Skin \& Laser Surgery Center of New England Boston, USA

A comprehensive discussion about laser treatment of scars will be presented. Following topics will be discussed in detail; Definition of scars, various types of scars, causes and patho-physiology of scars. All treatments option will be reviewed including chemical, surgical treatments followed by current laser treatments of various scars. Laser treatment option for surgical, hypertrophic, burn and acne scars will be presented. Treatment of Striae will be discussed as well. This will be followed by a presentation of laser induced scars.

FRAXELATED RADIOFREQUENCY DEVICE FOR ACNE SCARS

Babar K. Rao', MD, Sairah Khokher ${ }^{2}$, MD 
${ }^{1}$ Associate Professor and Chair at Department of Dermatology, Robert Wood Johnson Medical School

${ }^{2}$ Fellow at Department of Dermatology, Robert Wood Johnson Medical School

Background: Acne scars can be improved with various topical creams, chemical peels, dermal fillers, microdermabrasion, ablative and non-ablative laser therapy. Some of these treatments especilaly lasers and deep chemical peels can have significant side effects in darker skin types. Fraxelated RF Laser devices have been reported to have lower incidence of side effects in all skin photoypes.

Objective: To assess the effectiveness and safety of fraxelated radiofrequency device in treatment of acne scars in various skin phototypes.

Methods: Nine patients of ages 18 and above and of various skin phototypes were selected from a private practice and treated with a RF fraxelated device (E-matrix) for acne scars. Outcomes were assessed by photos taken before and after treatments, patient satisfaction, and physician assessment. Photos were taken before treatment and after treatment at 1 and 4 weeks intervals. In one patient confocal images were also taken to assess the effects of treatments on a cellular level. Results: Outcomes were measured by physician observation, subjective feedback received by patients, and comparison of before and after photographs. Most patients were satisfied and reported improvement in their acne scars and pores. By photographic comparison and physician assessment acne scars were improved as early as at 4 weeks post treatment. Downtime and side effects for the procedure were minimal in all skin phototypes.

Conclusion: In this small group of patients with various skin phototypes, fraxelated radio-frequency device improved acne scars with minimal side effects and downtime.

\section{LONG TERM EVALUATION OF PDL LASER IN DERMATOLOGY}

Eva Remlova ${ }^{1}$, Tatjana Dostalová ${ }^{2}$, Helena Jelínková ${ }^{3}$, Jana Vránováa $^{3}$, Leoš Navrátil ${ }^{4}$, Josef Rosina ${ }^{4}$

${ }^{1}$ AVE LASER CENTRUM, Olomouc, Czech Republic ${ }^{2}$ Charles University, $2^{\text {nd }}$ Medical Faculty, Department of Paediatric Stomatology, Prague, Czech Republic

${ }^{3}$ Czech Technical University in Prague, Faculty of Nuclear Sciences and Physical Engineering, Prague, Czech Republic

${ }^{4}$ Czech Technical University in Prague, Faculty of Biomedical Engineering, Kladno, Czech Rep.

Background: Pulsed dye laser (PDL) is frequently used for the treatment of skin vascular lesions. The active medium is the solution of organic dye Rhodamin $\mathrm{G}$ in ethylenglykol. The generating radiation wavelength of the rhodamin $\mathrm{G}$ is $595 \mathrm{~nm}$.
Purpose: The aim of the study is to demonstrate the efficiency of clinical therapy with PDL in dermatology.

Material and Methods: The group of 4000 patients with skin vascular lesions was retrospectively reviewed. Patients included in our study had different diagnosis and were observed in 10 years recall. All patients were treated in several sessions without anesthesia application. The non-ablative system PDL was based on selective photothermolysis.

Results: From results it was evident that the therapeutic effect of PDL was very high. The best one with only minor side effects has been reached by telengiectases, rosacea, PWS, posttraumatic scars, burns, striae, and warts.

Discussion and Conclusion: It was confirmed that PDL (595 nm, $1.5 \mathrm{~ms}, 7 \mathrm{~mm}, 9-11 \mathrm{~J} / \mathrm{cm}^{2}$ ) had the excellent therapy effect with minimal side effect.

\section{MELASMA: A COMMON PROBLEM IN SOUTH EAST ASIA \\ Naqiba Munshi \\ Elements MediSpa, Karachi, Pakistan \\ naqibamunshi@hotmail.com}

Background: Melasma is a common dermatological problem in South East Asia and causes great emotional suffering. There is no universally accepted form of treatment and different modalities offer various degrees of result.

Purpose: To be able to formulate right treatment parameters with lasers for majority of Melasma patients.

Methods: Melasma patients seeking treatment have tried various available options to treat their condition. Among these are Hydroquinones, Tretinoins, and various concentrations of Chemical Peels and lasers, etc. After an initial consultation and photo-documentation, patients are either put on a regime to prepare the skin or, in some cases, their laser sessions are started right away. Most of these cases have mixed types of Melasma with varying degree of Epidermal and Dermal component. 8-10 treatments are done at approximately two weeks interval .

I use Q-switched Nd-Yag laser (Revlite by Hoya Con Bio) and my parameters are $6 \mathrm{~mm}$ spot size, $2.5-3.5 \mathrm{~J} / \mathrm{cm} 2$. Multiple passes are done to reach a fair degree of erythema on the melasma areas. Rest of the face is treated on low setting to even out. For maintenance, I use skin lightening formulas (Kojic \&Azelaic acid, Vit C, Liquorice) along with Antioxidants and sun blocking creams. Currently, I am getting very good results with Elure (by Syneron), a melanozyme enzyme that breaks the pigment.

For some refractory cases, I use long pulse Nd-Yag laser (Gentle Yag by Candela) with $8 \mathrm{~mm}$ spot size, $0.3 \mathrm{~ms}$ pulse duration and about $12 \mathrm{j} / \mathrm{cm} 2$. Multiple passes are done in paint brush technique all over the face. 
Results: As we all know that Melasma is not a completely treatable condition. An optimum treatment which is result oriented with minimal downtime is acceptable to majority of the patients. There is pigment lightening in $70 \%$ of the cases along with textural smoothness, uniformity in skin color, reduction of pore size, bleaching of fine facial hair.

\section{TREATMENT OF 638 JAPANESE FEMALE} INFERTILITY PATIENTS WITH GAALAS DIODE

\section{LASER}

Toshio Ohshiro, Yuki Taniguchi, Takafumi Ohshiro, Katsumi Sasaki

Ohshiro Clinic, Japan Medical Laser Laboratory, Plastic and Reconstructive Surgery - Tokyo, Japan ohshiro@jmll.co.jp

Background: In the past 50 years, the tendency to postpone childbearing spread throughout the developing world. As the age increase, the functions of organs decrease. Biochemical changes are brought by numerous endogenous and exogenous factors and can have a profound effect on ovarian oocyte quality. Oocytes of poor quality may be the cause of women infertility and an important obstacle in successful assisted reproductive technologies (ART). Recently low reactive laser therapy (LLLT) is recognized as the promising adjunctive treatment for refractory infertility women.

Aim: The aim of our presentation is to assess the LLLT curative effect.

Subjects and Method: 814 patients presented to Ohshiro clinic for treatment of infertility from July 1st, 2000 till December, 2009 were enrolled in the analysis. We analyzed the therapeutic frequency and the therapeutic period (the number of menstrual cycle) between pregnant women and non-pregnant women.

Results: Results are expressed as means \pm standard error of mean. The statistical difference was determined by two-side Student's $t$ test and Mann-Whitney's $U$ test. Difference with P. 